\title{
A Preliminary Examination of the Impact of Working Memory Training on Syntax and Processing Speed in Children with ASD
}

\author{
Hélène Delage ${ }^{1}$ (D) Inge-Marie Eigsti ${ }^{2} \cdot$ Emily Stanford $^{1,4,6} \cdot$ Stephanie Durrleman $^{1,3,5}$
}

Accepted: 16 September 2021 / Published online: 1 November 2021

(c) The Author(s) 2021

\begin{abstract}
In addition to deficits in pragmatics, children with autism spectrum disorders (ASD) have weaknesses in complex syntax and working memory (WM). These two deficits may be closely related. Previous work investigated the effects of WM training in developmental language disorders and showed significant improvement in both WM and syntax. The current study tests the impact of $12 \mathrm{~h}$ of WM training across 8 weeks in 30 children with ASD, aged 5 to 11 . Results showed direct improvements on untrained WM tasks, as well as transfer effects to syntax and processing speed. Stronger WM led to better syntactic abilities. While they must be replicated, these exciting results provide impetus for further studies of WM interventions.
\end{abstract}

Keywords Autism spectrum disorder $\cdot$ Children $\cdot$ Working memory $\cdot$ Training $\cdot$ Syntax $\cdot$ Attention

Autism spectrum disorder (ASD) is a neurodevelopmental condition characterized by persistent deficits in social communication and social interaction, as well as restricted and repetitive patterns of behavior, interests and activities (DSM5, American Psychiatric Association, 2013). Language performance of children with ASD is highly variable, ranging from no language at all to fluent speech (Eigsti et al., 2011; Lim, 2018; Wan et al., 2011). Children with ASD present intellectual disabilities in 30-50\% of cases (Centers for Disease

Hélène Delage

helene.delage@unige.ch

1 Department of Psycholinguistics and Speech-Language Therapy, Faculty of Psychology and Educational Sciences, University of Geneva, 28 Blvd. Pont d'Arve, 1205 Geneva, Switzerland

2 Department of Psychological Sciences, University of Connecticut, Storrs, CT 06269, USA

3 Department of Medicine, Faculty of Science and Medicine, University of Fribourg, 5 Chemin du Musée, 1700 Fribourg, Switzerland

4 Present Address: Department of English Language and Literature, Faculty of Humanities, University of Geneva, 12 Blvd. des Philosophes, 1205 Geneva, Switzerland

5 Department of Linguistics, Faculty of Humanities, University of Geneva, 2 rue de Candolle, 1211 Geneva 4, Switzerland

6 Department of Psychology, Università degli Studi di Milano-Bicocca, 1 Piazza dell'Ateneo Nuovo, 20126 Milano, Italy
Control and Prevention, 2016), but contrary to popular belief, their language performance is not necessarily dependent on their IQ level (Durrleman \& Delage, 2016; Kjelgaard \& Tager-Flusberg, 2001). Thus, children with a low IQ may have language skills in the normal range while others may have language deficits with a normal non-verbal IQ, as is typically the case of children with Developmental Language Disorder (DLD). ${ }^{1}$ There is a consensus that pragmatic impairments are highly prevalent in individuals with ASD (Tager-Flusberg, 1996), and that these relate to core deficits in theory of mind (Baron-Cohen et al., 1985; Khimi, 2014). However, other areas of language may also be impaired, such as phonology (Wolk et al, 2016), lexicon (Kjelgaard \& Tager-Flusberg, 2001) and morphosyntax (Brynskov et al., 2017; Durrleman \& Delage, 2016; Durrleman et al., 2016; Oi, 2008, 2010; Riches et al., 2010; Silleresi et al., 2018; Terzi et al., 2014; Tuller et al., 2017; Zebib et al., 2013). Some 60 to $70 \%$ of children with ASD perform similarly to children with DLD on tasks assessing lexicon (Kjelgaard \& Tager-Flusberg, 2001), phonology (Zebib et al., 2013) and morphosyntax (Durrleman \& Delage, 2016; Silleresi et al., 2018). These findings have been interpreted to suggest a comorbidity between ASD and DLD, sometimes attributed to a shared etiology and common risk genotype (Bishop, 2010; but see Williams et al., 2008). High co-morbidity between the two populations suggests that

\footnotetext{
${ }^{1}$ Diagnosis of DLD includes severe and persistent language disorders that interfere with daily functioning in the absence of a specific biomedical condition, such as Down Syndrome (Bishop et al., 2017).
} 
training that has been shown to be effective in children with DLD could be equally beneficial in ASD, prompting the current study in which we train working memory (WM) in participants with ASD and observe transfer effects to complex syntax, as already demonstrated in children with DLD (Delage et al., 2020, 2021; Stanford et al., 2019).

\section{Working Memory in ASD}

Both ASD and DLD involve difficulties in executive functions (see McCrimmon et al., 2016 for ASD; Kapa \& Plante, 2015, for DLD), in particular in WM. WM is defined as the temporary storage and manipulation of information needed to perform complex cognitive tasks related to learning, reasoning and language processing (Baddeley, 2003). Although various WM models exist, such as Cowan (1999), Miyake et al. (2000), Engle (2002) or Barrouillet and Camos (2012), Baddeley's tripartite, multi-component, model of WM remains highly influential in psycholinguistics. This model integrates an attentional control system, the central executive and two subsystems: a phonological loop that stores and manipulates acoustic and verbal information, and a visuo-spatial sketchpad that stores and manipulates visual and spatial information.

The capacities of the phonological loop are assessed by simple-span verbal tasks (Barrouillet \& Camos, 2007). These tasks require simple maintenance and recall of verbal information (e.g., forward digit span, word and nonword spans). Simple spans can be further subdivided into item and serial order short-term memory (Majerus et al., 2006, 2009). Item memory refers to the storage of lexical items, including their semantic and phonological representations; serial refers to the order in which the items are presented. The capacities of the central executive are measured using complex-span tasks that typically add a dual or interfering task to a memory task, for example by asking participants to evaluate the truth value of a series of sentences, and then recall the final word in each sentence (Barrouillet \& Camos, 2007). Backward digit span also belongs to this category (Redick \& Lindsey, 2013), although whether it differs from forward digit span remains controversial (St Clair-Thompson, 2010).

Both simple and complex-span tasks reveal WM deficits in ASD (Alloway et al., 2009, 2016; Bennetto et al., 1996; Eigsti, 2009; Gabig, 2008; Joseph et al., 2005; Schuh \& Eigsti, 2012; Williams et al., 2006). Schuh and Eigsti (2012) found deficits in 18 English-speaking participants aged 9-17, with high-functioning ASD, in nonword repetition (simple span) as well as in listening recall task (complex span). In 21 French-speaking children and adolescents with ASD aged 5-16, Durrleman and Delage (2016) reported verbal WM impairment on both types of spans, on nonword repetition and forward as well as backward digit span. Despite occasional reports of preserved WM capacities in this population (see for example Alloway, 2018), a meta-analysis conducted by Habib et al. (2019) on 34 studies of children and adults with ASD ( $n=226$ in total) confirmed deficits in both verbal and visuospatial components of WM, where neither age nor IQ explained the observed WM differences. Another meta-analysis published by Wang et al. in (2017) reached the same conclusion, for both simple and complex spans. A meta-analysis which focused on more general executive functions in ASD (Demetriou et al., 2018) also pointed to a broad executive dysfunction in ASD, including WM deficits that were relatively stable across development.

\section{Attentional Capacities in ASD}

Although WM and attentional systems are conceptualized as distinct cognitive structures, they are closely related. An attentional component is included in all WM models (Baddeley, 2003; Barrouillet et al., 2004; Cowan, 1999); in Baddeley's model, the central executive is an attentionalcontrolling system which coordinates the more passive subsystems. Taking a developmental perspective, Garon et al. (2008)'s integrative framework model of executive functions includes a selective attention system which supports the further development of higher cognitive functions such as WM, inhibition and shifting. In this model, selective attention is a lower-order skill which consists of focusing attention on relevant stimuli while ignoring distracting information. Selective attention is typically assessed by asking subjects to identify visual or auditory target stimuli under various distracter conditions, as in the Test of Everyday Attention for Children (TEA-Ch, Manly et al., 1999). Higher-order aspects of attention, such as attention shifting, are typically assessed by asking subjects to switch attention to new stimulus dimensions, such as color or shape, as in the Dimensional Change Card Sort (DCCS, Frye et al., 1995).

Noterdaeme et al. (2001) compared the attention profiles of 19 participants with ASD (aged 7 to 21) to participants with DLD and typical development, matched for age, sex and non-verbal IQ. Although both ASD and DLD groups showed impaired executive functions (inhibition and attention shifting), only the DLD group displayed additional deficits in lower-order skills (sustained auditory attention and selective attention). In the same vein, Tye et al. (2014) compared children aged 8 to 13 with ASD and with Attention Deficit/Hyperactivity Disorder (ADHD) with IQ in the average range, on a flanker-cued continuous performance task. They showed that children with ADHD displayed deficits in low-order skills, such as attentional orienting, whereas those with ASD showed deficits in conflict monitoring and 
response preparation. Studies of sustained attention in children with ASD have conflicting results, with some documenting deficits (e.g., Chien et al., 2014, 2015; Vivanti et al., 2017) and others not (e.g., Garretson et al., 1990; Johnson et al., 2007). These differences could be explained by the heterogeneity of participant ages and nonverbal cognitive functioning. In a review of attention, inhibition and cognitive flexibility research in average-IQ children with ASD, Sanders et al. (2008) identified frequent deficits in orienting attention, inhibition and shifting, but apparently typical capacities in sustained attention. A meta-analysis conducted by Demetriou et al. (2018) also confirms the deficit in executive functions in ASD, notably in mental flexibility. The current study measures the impact of these cognitive functions in ASD on linguistic abilities, and in particular how WM may impact syntax.

\section{Working Memory and Syntax}

Executive functions are linked to syntactic capacities, in typically-developing children (e.g., Finney et al., 2014; Ibbotson \& Kearvell-White, 2015; Viterbori et al., 2012; White et al., 2017), in children who present either syntactic difficulties, such as children with DLD (Ellis Weismer \& Thordardottir, 2002; Im-Bolter et al., 2006; Montgomery, 2008; Montgomery et al., 2009), and in executive dysfunction such as ADHD (Stanford \& Delage, 2020).

While many of these studies focused primarily on selective attention and attention shifting, WM (and verbal WM in particular) is also linked to syntax. For example, Adams and Gathercole (2000) and Willis and Gathercole (2001) reported that children aged 3-5 years with lower phonological loop abilities (evaluated with forward digit span and nonword repetition) produced significantly fewer correct complex sentences compared to children with better WM performance. De Abreu et al. (2011) compared the role of simple and complex spans on the language performance of typically-developing 5-year-olds. They reported that simple spans (assessed via forward digit span and nonword repetition) were more closely related to lexical abilities, and complex spans (assessed via backward digit span and counting span) were most closely related to syntactic comprehension. Montgomery et al. (2008) compared the role of simple spans (assessed via nonword repetition) and complex spans (assessed via listening span) on complex sentence comprehension in children aged 6 to 12, and found that complex (but not simple) spans explained a significant part of the variance $(30 \%)$ in syntactic comprehension scores.

Delage and Frauenfelder (2019) conducted a detailed assessment of the relationship between simple and complex components of WM and complex syntax (assessed in comprehension, repetition and spontaneous production) in 48 monolingual French-speaking children aged 5 to 12 . They found a strong predictive relationship between WM and syntax, with no effect of non-verbal IQ. This relationship was even more pronounced for more complex syntactic structures, such as relative clauses with multiple versus single levels of embedding and object relatives versus subject relatives. Complex spans (particularly counting span) explained the largest part of the variance in the production of embedded utterances in spontaneous speech, whereas the production of simple sentences (without any embedding) was not predicted by WM. These results highlight the link between WM and complex syntax: "Hence, it seems that processing complex sentences, even in a natural contact, depends on WM capacities, which is not the case for simple sentences that contain fewer syntactic operations, such as the multiplicity of internal and external merges" (Delage \& Frauenfelder, 2019, p. 165).

\section{Working Memory and Syntax in DLD}

Numerous studies have examined the link between WM and syntax in children with atypical development. Stanford (2020) reported strong correlations between WM (assessed via forward and digit span) and expressive syntax in 20 French-speaking children with ADHD aged 6 to 10. Montgomery and Evans (2009) showed a significant link between WM and comprehension of complex sentences in 24 children with DLD aged 6 to 12 , a link which was stronger than that in the typically-developing comparison group. Frizelle and Fletcher (2015) identified close relationships between WM and complex sentence repetition in 35 children with DLD aged 6-7, echoing findings from Riches et al. (2010) in 14 adolescents with DLD aged 14 to 16 . Testing a clinical marker of DLD, namely the 3rd person accusative clitic in French (e.g., il le lave 'he's washing him/it'), Durrleman and Delage (2016) found a correlation between this grammatical marker and a measure of complex span (backward digit span) in 22 participants with DLD aged 5 to 16 . This study also probed elicited production of first-person accusative clitics (e.g., il me lave 'he is washing me'), which do not require the morphological marking of gender and number, ${ }^{2}$ and found no correlation with WM.

Delage and Frauenfelder (2020) evaluated the performance on complex syntax and WM of 28 French-speaking children with DLD aged 5 to 14 , who completed three simple-span tasks (forward digit span, serial order memory and nonword repetition) and three complex-span tasks (backward digit span, counting span and running span). Results highlighted the severe deficits of children with DLD in both syntax and WM; further, deficits were largely uncorrelated with

\footnotetext{
$\overline{2}$ See Delage et al., (2016) for further analyses.
} 
age (one single correlation on 11 measures), in spite of the large age range of the group, whereas such correlations were present in 28 aged-matched peers (correlations on eight of 11 measures). WM skills predicted the comprehension and repetition of complex sentences, controlling for non-verbal IQ, and simple spans (especially, the serial component of verbal short-term memory) predicted syntactic measures in spontaneous language.

Given that WM limitations in children with DLD predicted their (deficient) complex syntax abilities, WM training in this population was the logical continuation of this research area. Our previous work (Delage et al., 2020, 2021; Stanford et al., 2019) evaluated the effects of WM training on syntactic abilities of children with DLD via a novel WM training program, Magic Memory (Delage et al., 2017). This program included exercises targeting the aspects of WM most predictive of syntax (Delage \& Frauenfelder, 2019, 2020). 32 children with DLD (aged 6-12) received 8 weeks of Magic Memory training; an age-matched DLD comparison group completed an alternative training. Findings revealed both direct benefits on untrained WM tasks and indirect benefits on expressive syntax. Specifically, the WM-training group had more accurate elicited production of 3rd person accusative clitics (Stanford et al., 2019) and repetition of complex sentences (Delage et al., 2020, 2021). The active comparison group showed no such improvements, suggesting the specificity of the observed effects of the target WM training.

\section{Working Memory and Syntax in ASD}

In summary, language profiles in both ASD and DLD suggest difficulties with complex structures such as accusative clitics (Durrleman \& Delage, 2016; Prevost et al., 2018), relative clauses (Riches et al., 2010; Silleresi et al., 2018), morphological marking (Modyanova et al., 2017; Roberts et al., 2004), wh-questions (Durrleman et al., 2016; Prévost et al., 2017; Zebib et al., 2013), passives (Ambridge et al., 2021; Durrleman et al., 2017) and embedded clauses (Durrleman et al., 2019; Silleresi et al., 2018). WM deficits are also attested in both ASD and DLD (e.g., Habib et al., 2019 for ASD or Kapa \& Plante, 2015 for DLD). As in DLD, there appears to be a specific relationship between WM and syntax in children with ASD; those children who have the most difficulty with language tasks also have more difficulty with phonological WM (Kjelgaard \& Tager-Flusberg, 2001). Hill et al. (2015) distinguished between ASD children with and without comorbid language deficits; children in the former group had more severe WM deficits than the latter. In Durrleman and Delage (2016), 21 French-speaking participants with ASD aged 5 to 16 and 22 age-matched children with DLD completed standardized measures of expressive grammar and the production of a clinical marker of DLD in French, i.e. accusative clitics, alongside measures of verbal WM (forward and backward digit spans). Both groups showed impaired WM skills, which also correlated with production of 3rd person accusative clitics; non-verbal IQ did not correlate with any measure of syntax. Weismer et al. (2017) compared children with ASD and DLD (30 per group, mean age 10 years) in an N-back WM task and a complex grammatical judgement task, and found performance to be highly correlated in both groups. Similarly, Schuh and Eigsti (2012) demonstrated the presence of a strong relation between phonological WM (assessed via nonword repetition) and syntactic performance (assessed via the syntactic scale of CELF-4, Semel et al., 2003) in individuals with ASD and average cognitive abilities, ages 9-17. Riches et al. (2010) reported correlations for performance on complex sentence repetition, nonword repetition, and backward digit span in 16 adolescents with ASD plus language impairment, aged 14 to 15 . In sum, while fewer studies have investigated this issue, there is robust evidence linking WM and syntax in ASD. As in DLD, WM limitations in ASD likely impact the acquisition of complex syntax, and improving WM capacities via a dedicated training program could free up cognitive resources to deal more effectively with syntax. The current study addresses this hypothesis.

\section{Research Questions}

The empirical data presented above, particularly our training studies in DLD (Delage et al., 2020, 2021; Stanford et al., 2019), suggest that specific WM training could have a positive impact on the mastery of complex syntax in children with ASD. We extended the methods of the DLD WM training study to a population of children with ASD, using the Magic Memory (Delage et al., 2017) training program. We predicted (1) a significant increase in WM scores following training (direct effects on WM); and (2) a significant improvement in complex syntax (transfer effects on syntax). This study did not include an active control group of participants receiving an alternative training regimen, since our previous studies with children with DLD or typical development (Delage et al., 2020, 2021; Stanford et al., 2019) found no improvement in WM or syntax for participants receiving an alternative training program focusing on academic skills. There was no obvious reason to anticipate different results with a second active control group of ASD participants; thus, we focused our recruitment efforts on children to be included in the target (WM) training program.

The current study also included attentional measures, in light of the observation that WM is closely linked to the attentional system (Garon et al., 2008; Majerus et al., 2009; Veer et al., 2017) and children with ASD are known to experience difficulties in executive functions (Demetriou et al., 
Fig. 1 Timeline of study activities

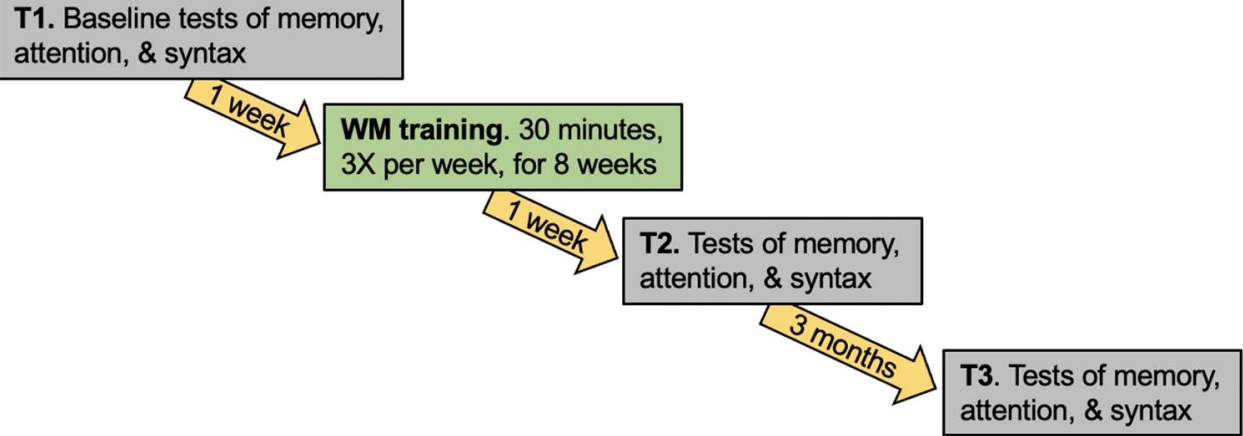

2018). Given that intensive training might have a specific impact on attention, we predicted (3) an improved performance in attentional measures after training (transfer effects on attention). Finally, participants completed a longterm follow-up three months after training. We predicted that 4) potential effects on WM, syntax and attention would be maintained after three months (long-term effects).

\section{Methods}

For all participants, the study procedures were identical, see Fig. 1, and follow the procedures used in our previous studies in children with TD and DLD of the same age (Delage et al., 2020, 2021; Stanford et al., 2019). The training was delivered on iPad (that we provided), with frequent positive feedback (encouragements, rewards, playful animations) to boost motivation. Training sessions were carried out by caregivers at home under the supervision of speech-language therapy graduate students. These graduate students contacted parents on a weekly basis to ensure that the training program was being appropriately followed and visited participants two to three times a month to track the progress of the training regime. The graduate students also performed the different pre- and posttests and the same student always worked with the same child throughout the study. To ensure the fidelity of the analyses, all tests were recorded and the transcripts and scores were checked by two experts in the field, authors 1 and 3, respectively.

Baseline (T1) abilities were established via pre-tests 1 week prior to the first training session, comprising two 45-min sessions to assess memory, syntactic and attentional skills. Participants then completed the 8-week intensive training regimen of three 30-min sessions per week for a total of $12 \mathrm{~h}$. Tests were completed again one week after training (T2) with exactly the same structures but different items, matched in frequency, length and complexity, to avoid practice effects. There were two different test versions, A and $\mathrm{B}$, and administration order was counterbalanced such that half of the participants completed version A pre-tests and version B post-tests, and the other half completed the opposite order. Post-tests (T3) were administered three months after T2, to assess the long-term stability of effects. Participants completed the same version (A or B) at T3 that they had completed at T1, five to six months earlier. As indicated on Fig. 1, the whole process lasted 5 months and 2 weeks. All participants completed the entire set of tests at each timepoint (T1, T2 and T3). All test sessions were of equivalent duration, lasting approximately $90 \mathrm{~min}$.

\section{Participants}

We recruited 30 French-speaking children (3 girls) with ASD ages 5 to $11(M=8 ; 8, S D=1 ; 8)$ from speech-language centers and specialized schools in the Geneva and Paris regions, which we had contacted directly to present the study and its clinical objectives. This age range was chosen since it corresponds to the ages of children for whom relationships between WM and complex syntax had previously been identified (Delage \& Frauenfelder, 2019, 2020; Durrleman \& Delage, 2016). We also chose structures known to be fairly well mastered from the age of 6 in typical development, for producing accusative clitics (Delage et al., 2016; Zesiger et al., 2010) and root questions (Jakubowicz, 2011), for repeating relative clauses (Frizelle \& Fletcher, 2014; Frizelle et al., 2017) as well as for comprehending complement sentences such as those tested here (Durrleman et al., 2019). Moreover, in our previous training studies using the same materials and protocols, we reported that TD children (aged 6-12) trained on WM showed improved WM performance thanks to the WM training, while their syntactic scores did not improve, given that performance approached ceiling both prior to and following training (Delage et al., 2021; Stanford et al., 2019).

Inclusion criteria were: (i) meeting DSM-5 (American Psychiatric Association, 2013) criteria for ASD according to the Autism Diagnostic Observation Schedule, ADOS (Lord et al., 2002; translated by Rogé et al., 2015) and/or the ADI-R (Rutter et al., 2003a, 2003b; translated by Rogé et al., 2011). The diagnosis of ASD was given by a child psychiatrist or psychologist with ASD expertise; (ii) low scores ( $\leq 1$ SD below the mean) on standardized tests of 
Table 1 Standardized assessments of non-verbal reasoning, expressive grammar and working memory

\begin{tabular}{llllll}
\hline & Chronological age & Non-verbal reasoning & Expressive grammar & WM Simple span & WM Complex span \\
\hline M (SD) & $8 ; 8(1 ; 8)$ & $-0.6(1.4)$ & $-3.7(2.1)$ & $-1.2(1.2)$ & $-2.5(1)$ \\
Range & $5 ; 11-11 ; 10$ & $-4.2-1.7$ & -8.9 to -1 & $-4.1-1.1$ & -5 to -1 \\
\hline
\end{tabular}

WM was assessed using the Evaluation of Working Memory Test (Boutard \& Gatignol, 2015). Nonverbal IQ was estimated using Raven's Progressive Matrices. Expressive grammar was assessed using the BILO-3C (Khomsi et al., 2007). Data are shown as Z-scores, calculated with respect to the normative scores as reported in test manuals

syntax and complex WM; and (iii) French as a first language. For all participants, we used the French adaptation of the Childhood Autism Rating Scale (CARS, Schopler et al., 1980; translated by Rogé, 1989) to assess the severity of autistic symptomatology, see individual scores in Appendix A. Non-verbal reasoning was assessed using Raven's progressive matrices (Raven \& Court, 1998). Five children were included in the study despite a low Raven's score $(<2 \mathrm{SD})$ because the examiners determined that these children had sufficiently strong comprehension and attention to participate. In addition, six children were simultaneous bilinguals, ${ }^{3}$ two had comorbid ADHD and two others followed specialized education (see Appendix A). Table 1 presents demographic data and T1 standardized test scores for measures of non-verbal reasoning (Raven's score), expressive grammar (a sub-test of the BILO-3C battery, Khomsi et al., 2007) and WM (Evaluation of Working Memory Test, Boutard \& Gatignol, 2015). Two composite simple- and complex-span scores were calculated for the WM standardized tasks.

Nonverbal skills were age-typical overall; 14 children had above-average Raven's scores. In expressive syntax, all children obtained low scores, with 20 scoring more than 2 SD below the mean. All children obtained low complex-span WM scores ( $>1$ SD below the mean for their age); simple span scores were more variable, and the difference between simple and complex spans was significant, $t(58)=4.52$, $p<0.001$. Appendix A provides these results in detail.

This study was approved by the Ethics Committee of the Faculty of Psychology and Educational Sciences of the University of Geneva as well as from the Geneva Cantonal Ethics Commission and was also declared at 'La Commission Nationale de l'Informatique et des Libertés (CNIL)' in France. Parents provided written informed consent for participation.

\footnotetext{
${ }^{3}$ We compared the performance of these 6 children to that of other (monolingual) children with ASD $(\mathrm{N}=24)$. These two groups did not differ for expressive grammar $(p=.1)$, non-verbal reasoning $(p=.4)$, or simple and complex-span composite scores (respectively $p=.9$ and $p=.1$ ). As such, performance for monolinguals and bilinguals is reported as a group.
}

\section{Pre- and Post-training Tests: Working Memory}

Before and after training, children completed tests assessing WM with three simple span tasks and two complex span tasks, see Table 2.

\section{Pre- and Post-training Tests: Syntax}

Before and after training, children completed three measures assessing syntactic knowledge, shown in Table 3. Each measure included two paired versions (A and B) for counterbalancing. To adapt the measures, we split the items in the initial tasks into two, leaving two versions that were matched on (1) lexical frequency and (2) the type of syntactic structure targeted.

\section{Elicited Production of Root Questions}

In this task, adapted from Jakubowicz (2006), the experimenter showed the child a picture in which a character performs an action with part of the image hidden. The child was prompted to ask the character a question about the hidden part (e.g., "Look, there is a rabbit pushing someone, but we don't know who. Ask him"). The target responses consisted of subject $(\mathrm{N}=3)$ or object questions $(\mathrm{N}=9)$. For object questions, the child could formulate questions with a $w h$ fronted object (1 and 2) or wh-in situ questions (3), which are less grammatically complex but very frequent in spoken French.

(1) "Qui pousses-tu?" ('Who push you').

(2) "Qui tu pousses?" ('Who you push').

(3) "Tu pousses qui?" ('You push who').

\section{Elicited Production of Accusative Clitics}

In this task adapted from Tuller et al. (2011) and Delage et al. (2016), the child saw images on a computer and then answered questions requiring the use of a $3^{\text {rd }}$ person accusative clitic (e.g. what is the doctor doing with the boy? Expected response: "il le pèse" 'he's weighing him'). Each version included 12 trials. Responses typically contained (i) the target accusative clitic, (ii) a lexical unit (il 
Table 2 Pre- and post-training tests of working memory

\begin{tabular}{|c|c|c|}
\hline Task & Description & Scoring \\
\hline \multicolumn{3}{|l|}{ Simple span tasks } \\
\hline $\begin{array}{l}\text { Forward digit recall } \\
\text { (WISC IV, Wechsler, 2005) }\end{array}$ & $\begin{array}{l}\text { The experimenter says aloud a series of digits increasing in } \\
\text { length from } 2 \text { to } 9 \text {; participants have to immediately repeat } \\
\text { them aloud in the same order. Testing is discontinued when } \\
\text { participants fail two trials in a row. }\end{array}$ & Number of correctly repeated sequences \\
\hline $\begin{array}{l}\text { Nonword repetition } \\
\text { (BELEC, Mousty et al., } \\
\text { 1994) }\end{array}$ & $\begin{array}{l}\text { The experimenter says aloud a non-word, which the participant } \\
\text { must repeat immediately. Words increase in length from 1-5 } \\
\text { syllables and in phonological complexity (with Consonant- } \\
\text { Vowel and Consonant-Vowel-Consonant structures), such as } \\
\text { moga, juséga or kragrinblan. There is no stop criterion. A trial } \\
\text { is marked as incorrect when participants omit, add or misorder } \\
\text { one phoneme. }\end{array}$ & Number of correctly repeated syllables \\
\hline $\begin{array}{l}\text { Serial order word span } \\
\text { (Majerus, 2008) }\end{array}$ & $\begin{array}{l}\text { This task tests the ability to retain serial order information. The } \\
\text { experimenter says aloud sequences of familiar animal names } \\
\text { along with the order in which these animals finished in a race. } \\
\text { Participants must place animal cards in the order in which they } \\
\text { finished; thus, they must store and recall the serial order of } \\
\text { items but not the item names. Sequence length increases from } \\
\text { two to seven. Testing is discontinued when participants fail } \\
\text { two trials in a row. }\end{array}$ & Number of items retrieved in the correct order \\
\hline \multicolumn{3}{|l|}{ Complex span tasks } \\
\hline $\begin{array}{l}\text { Backward digit recall } \\
\text { (WISC IV, Weschler, 2005) }\end{array}$ & $\begin{array}{l}\text { The experimenter says aloud a series of digits increasing in } \\
\text { length from } 2 \text { to } 9 \text {; participants have to immediately repeat } \\
\text { them aloud in reversed order. Testing is discontinued when } \\
\text { participants fail two trials in a row. }\end{array}$ & Number of correctly repeated sequences \\
\hline $\begin{array}{l}\text { Counting span } \\
\text { (Case et al., 1982) }\end{array}$ & $\begin{array}{l}\text { Participants are asked to count the number of blue dots on each } \\
\text { page; after completed from } 1 \text { to } n \text { pages, and signaled by a } \\
\text { smiley face, they are asked to recall the tallies from each of } \\
\text { the previous pages in the correct order. The number of pages } \\
\text { increases until a stop criterion (two failures in a row) was } \\
\text { reached. Testing only proceeds if the child is able to count col- } \\
\text { lections of up to } 11 \text { items. }\end{array}$ & Number of digits retrieved in the correct order \\
\hline
\end{tabular}

Table 3 Pre- and post-training tests of syntax

\begin{tabular}{lll}
\hline & Tasks & Item structure (number of trials) \\
\hline Elicited production & Root questions & $\mathrm{N}$ subject and object questions (/12) \\
& & $\mathrm{N}$ wh-fronted object questions (/9) \\
Repetition & Complex sentence repetition & $\mathrm{N}$ correct clitics $(/ 12)$ \\
& & $\mathrm{N}$ correct syllables $(/ 210)$ \\
Comprehension & Complement sentences & $\mathrm{N}$ respected degree of embedding (/15) \\
& & $\mathrm{N}$ correct responses $(/ 12)$ \\
\hline
\end{tabular}

pèse le garçon 'he's weighing the boy'); this response is grammatical but infelicitous as it unnecessarily repeats the full lexical unit; (iii) a clitic with a gender error (ex: *il la pèse 'he's weighing her'), or (iv) an omitted clitic (*il pèse 'he's weighing').

\section{Complex Sentence Repetition}

To test the ability to repeat syntactically complex sentences, we used a sentence repetition task created by Delage and Frauenfelder (2019) that required participants to immediately repeat sentences read to them by the experimenter. The task comprised 23 sentences, all 14 syllables long: Eight syntactically simple sentences (without any embedding) and 15 syntactically complex sentences. The complex sentences 
varied in target structure (5 subject and 10 object relatives) and in the number of embeddings (one, two or three). Target structures thus contained either a subject (as in 4) or an object relative (5), and an expected degree of embedding; examples (4) and (5) have one degree of embedding and (6) and (7), respectively, have two and three levels of embedding. Appendix B presents the entire set of sentences for the two versions (A and B), which were matched for length, syntactic structure and frequency.

(4) La maîtresse voit le garçon [qui lit un livre sur Noël] 'The teacher sees the boy who is reading a book about Christmas'

(5) C'est un chat [que caressent tous les enfants après l'école] 'It's a cat that all of the children pet after school'

(6) Je crois [que la fille préfère le chien [qu'elle a colorié]] 'I think that the girl prefers the dog that she colored'

(7) Il pense [qu'elle dit [que le garçon déteste la fille [qui pleure]l]

'He thinks that she says that the boy hates the girl who is crying'

As the task progressed, the structures the children were asked to repeat became increasingly more complex. Scoring for the sentence repetition task considered (i) the number of syllables which were correctly repeated, disregarding possible mispronunciations; (ii) inclusion of the target structure (e.g. an object relative), and (iii) inclusion of the expected degree of embedding (one, two or three). Considerations (ii) and (iii) focused only on syntactic properties. Thus, if the response included the correct structure and/or the expected level of embedding, it was scored as correct even if the response included an incorrect word (e.g., if a child said "the woman" instead of "the teacher"). Responses were digitally recorded. Trained research assistants transcribed and coded all responses, which were reviewed in full by the first and the third authors.

\section{Comprehension of Complement Sentences}

Complementation skills were assessed using a task adapted from De Villiers and Pyers (2002). Children were presented with 12 scenes in which a character reported an event to another. Half of the items included an accurate reporting of the event, and half involved a mistaken or false belief. Children were required to recall the content of the (true or false) complement. For example, children heard: "The girl asks Dad what Mom is doing and Dad answers that Mom is working." For true complements, the story continued: "Look, Mom is really working" while for false complements, children heard: "But look, Mom is actually taking a nap in the office." In both instances, the test question was: "What does Dad say that Mom is doing?" (while pointing to the first picture); see Appendix C.
The child had to point to the picture representing the content of the complement initially heard (i.e., depicting Mom working).

\section{Pre- and Post-training Tests: Attention}

\section{Selective Attention}

Visual selective attention capacity was assessed via the Sky Search task (TEA-ch, Manly et al., 2006), which required participants to identify and circle pairs of identical spaceships from a page of visually-similar stimuli while ignoring distractors. Forty-nine spaceships were displayed and 20 were identical pairs. Speed (in milliseconds) and accuracy (number of correct targets) were the measures of interest.

\section{Processing Speed and Inhibition}

Performance on the Opposite Worlds task (TEA-ch, Manly et al., 2006), which was made up of two conditions, served as an indicator of attentional control/shifting. In the Same World condition, which measured processing speed, participants were presented visually with a path along which the digits 1 and 2 were scattered. The participants were asked to follow the path with their finger, naming each digit out loud (i.e. saying "one" each time they saw the digit 1 and "two" each time they saw the digit 2). In the Opposite World condition, which measured inhibition and response modification, the participants were instructed to say "one" when they saw a printed " 2 " and "two" when they saw a printed " 1 ". Errors resulted in a time penalty as participants were prevented from proceeding along the path to the subsequent digit until the error had been corrected. In total, the participants saw two worlds with Same World rules and two worlds with Opposite World rules that were presented in the following order: Same World 1-Opposite World 1Opposite World 2-Same World 2. Scores were calculated as the average time to complete the Same World and Opposite Worlds conditions.

\section{Working Memory Training Program}

The WM training was delivered via iPad using the same Magic Memory program used in our previous training studies (Delage et al., 2020, 2021; Stanford et al., 2019). In this adaptive program, the level of difficulty increased as a function of a child's progress. Five different activities, detailed in Appendix D, were presented in random order. All participants followed the same activities (five activities at each training session), with identical rhythm trials (5 min per activity). Activities targeted serial-order memory, WM updating and dual-task processing. In the serial-order memory activity, the child heard a series of familiar monosyllabic 
Table 4 Pearson correlations between composite WM scores and measures of syntax

\begin{tabular}{llllll}
\hline & Elicited production & & Complex sentence repetition & Complement sentence comprehension \\
\cline { 2 - 3 } & Root question accuracy & Clitic accuracy & N correct syllables & N correct responses \\
\hline Simple span composite & 0.31 & 0.29 & $0.34( \pm)$ & 0.26 \\
Complex span composite & $\mathbf{0 . 4 2} *$ & $\mathbf{0 . 3 7 *}$ & $\mathbf{0 . 5 2 * *}$ & $\mathbf{0 . 4 2 *}$ \\
\hline
\end{tabular}

Notations in bold indicate statistically significant results

$* * p<.01 ; * p<.05 ;( \pm)$ marginally significant $(p<.07) ; \mathrm{df}=30$

words and used a finger to drag the corresponding images into a train car in the order of presentation. The WM updating activity was an $n$-back task in which participants clicked an object (on the screen) if it appeared one, two or three trials previously. In the dual-task processing activity, the child had to retain an ordered list of familiar auditory stimuli (such as household objects, animal noises or musical instruments) while simultaneously performing a secondary task (a visual comparison of quantity task).

\section{Results}

After verifying that variables met standard assumptions of normality and heterogeneity, we checked for correlations between WM scores and syntax, as well as correlations of $\mathrm{WM} /$ syntax to clinical variables (i.e., age, non-verbal reasoning and autistic symptomatology). As a first step in the analyses, we created composite variables for WM, syntax, and attention measures (see "preliminary analyses" for details of these calculations). These composites were subjected to repeated-measures ANOVAS, to test for a main effect of the intervention (T1, T2, T3) on WM (direct effects) and syntax and attention (transfer effects). Those composite measures that showed significant change over time were further subjected to repeated-measures ANOVAs to compare performance from $\mathrm{T} 1$ to $\mathrm{T} 2$ (intervention effects) and from T1 to T3 (long-term effects); we also conducted exploratory analyses of individual WM, syntax, and attention measures, to identify specific domains where the intervention had the greatest impact. Finally, additional analyses probed clinical and cognitive predictors of changes in WM and syntactic ability.

\section{Preliminary Analyses}

Before exploring the effects of WM training, we ascertained whether WM and syntax were correlated at T1-Baseline, as in previous studies (Durrleman \& Delage, 2016; Schuh \& Eigsti, 2012). We calculated unit-weighted standardized (Z-score) composite scores for simple and complex spans; each measure contributed equally to the composite. The simple span composite was the average of forward digit recall and serial order word span $Z$-scores; these individual measures were highly correlated, $r(30)=0.60, p<0.001$. Nonword repetition (phonological WM) was excluded from this composite, as it was uncorrelated with serial order word span, $r(30)=0.29, p=0.11$. The complex span composite was the average of backward digit recall and counting span Z-scores, which were also highly correlated, $r(30)=0.47$, $p=0.006$. Results showed that the complex but not simple span composite correlated with all syntactic measures; see Table 4 . We also tested correlations of syntax and WM with age, non-verbal reasoning (Raven's matrices) and autistic symptomatology (CARS score); none were significant. The syntax composite was calculated as the average of the $Z$-scores of (1) Elicited production of root questions, (2) Elicited production of accusative clitics, (3) Sentence repetition, and (4) Comprehension of complement sentences. The attention composite was calculated as the average of the $Z$-scores of (1) Sky Search and (2) Opposite Worlds tasks.

\section{Improving Working Memory: Direct Effects}

To test whether WM training led to significant improvements in WM performance, we performed an initial repeatedmeasures ANOVA on T1, T2 and T3 scores. Both the simple WM composite scores, $F(1,29)=27.89, p<0.001$, Cohen's $f=0.93$, and complex WM composite scores, $F(1$, 28) $=185.89, p<0.001$, Cohen's $f=2.48$, showed significant main effects of training with large effect sizes. As such, we performed follow-up analyses to compare T1 with T2, for each of the WM measures; scores and statistics are presented in Table 5. Results indicated a significant effect of training, with a medium to large effect size, for all WM tasks, with improvements from $\mathrm{T} 1$ to $\mathrm{T} 2$.

\section{Improving Syntax: Transfer effects}

Repeated-measures ANOVAs tested whether training effects transferred to syntax. An initial repeated-measures ANOVA on T1, T2 and T3 composite syntax scores revealed a significant effect of training with large effect size, $F(1,26)=98.16, p<0.001$, Cohen's $f=1.86$. As such, 
Table 5 Repeated-measures ANOVA on working memory measures

\begin{tabular}{|c|c|c|c|c|c|c|c|c|}
\hline \multirow[b]{3}{*}{$\mathrm{N}$ participants } & \multirow{2}{*}{$\begin{array}{l}\text { Pretest T1 } \\
\text { M (SD) }\end{array}$} & \multirow{2}{*}{$\begin{array}{l}\text { Posttest T2 } \\
\text { M (SD) }\end{array}$} & \multirow[t]{2}{*}{ T1-T2 Effect of Time } & \multirow{2}{*}{$\begin{array}{l}\text { Posttest T3 } \\
\text { M (SD) }\end{array}$} & \multirow[t]{2}{*}{ T1-T2-T3 Effect of Time } & \multicolumn{3}{|c|}{ Post hoc HSD } \\
\hline & & & & & & $\mathrm{T} 1-\mathrm{T} 2$ & $\mathrm{~T} 1-\mathrm{T} 3$ & $\mathrm{~T} 2-\mathrm{T} 3$ \\
\hline & 30 & & & 26 & & & & \\
\hline $\begin{array}{l}\text { Forward digit recall } \\
(\max =16)\end{array}$ & $4.7(1.6)$ & $5.8(1.8)$ & $\begin{array}{l}F(1,29)=12.73 \\
p<.001, \eta^{2}=.31\end{array}$ & $5.4(1.5)$ & $\begin{array}{l}F(2,50)=8.56 \\
p<.001, \eta^{2}=.25\end{array}$ & $p<.001$ & $p=.02$ & $p=.5$ \\
\hline $\begin{array}{l}\text { Nonword repetition } \\
(\max =80)\end{array}$ & $40.9(13.6)$ & $46.3(9)$ & $\begin{array}{l}F(1,29)=6.84 \\
p=.014, \eta^{2}=.19\end{array}$ & $45.1(12.9)$ & $\begin{array}{l}F(2,50)=3.91 \\
p=.02, \eta^{2}=.13\end{array}$ & $p=.09$ & $p=.03$ & $p=.9$ \\
\hline $\begin{array}{l}\text { Serial order word span } \\
(\max =81)\end{array}$ & $19.2(11.3)$ & $30.3(10.2)$ & $\begin{array}{l}F(1,29)=49.92 \\
p<001, \eta^{2}=.60\end{array}$ & $27.5(12.5)$ & $\begin{array}{l}F(2,50)=17.03 \\
p<.001, \eta^{2}=.40\end{array}$ & $p<.001$ & $p<.001$ & $p=.4$ \\
\hline $\begin{array}{l}\text { Backward digit recall } \\
(\max =16)\end{array}$ & $4.1(2.3)$ & $5.4(1.9)$ & $\begin{array}{l}F(1,29)=16.42, \\
p<001, \eta^{2}=.36\end{array}$ & $4.5(2.2)$ & $\begin{array}{l}F(2,50)=9.92 \\
p<.001, \eta^{2}=.28\end{array}$ & $p<.001$ & $p=.4$ & $p=.01$ \\
\hline $\begin{array}{l}\text { Counting span } \\
(\max =81)\end{array}$ & $8.6(9.7)$ & $12.6(13.9)$ & $\begin{array}{l}F(1,29)=11.10 \\
p=002, \eta^{2}=.28\end{array}$ & $11(13.9)$ & $\begin{array}{l}F(2,50)=5.06 \\
p<.01, \eta^{2}=.17\end{array}$ & $p=.008$ & $p=.1$ & $p=.5$ \\
\hline
\end{tabular}

Notations in bold indicate statistically significant results

T3 data include only 26 out of 30 participants, four children having not been retested due to the coronavirus COVID-19 pandemic

we performed follow-up analyses to compare T1 with T2, for each of the syntax assessments; scores and statistics are presented in Table 6. Each of the measures showed a mean increase in accuracy, though not all changes were statistically meaningful. Of the four elicited syntactic production measures, root questions significantly improved between $\mathrm{T} 1$ and T2; of these root questions, only object questions, including $w h$-in situ items, showed significant change, $t(29)=-2.2, p=0.03, d=0.4$. There was no significant change in $w h$-fronted questions or object clitic productions. For complex sentence repetition, the number of correctly repeated syllables significantly improved from T1 to T2, with a medium-to-large effect. This result cannot only be explained by better memory, because repetition accuracy for simple sentences (which contained an identical number of syllables) showed no significant improvement, $t(29)=-1.2, p=0.2$. The percentage of sentences in which the degree of embedding was respected, independently of the lexical units, also improved. Finally, the children also showed a significant improvement in complement sentence comprehension between $\mathrm{T} 1$ and $\mathrm{T} 2$.

\section{Improving Attentional Skills: Transfer Effects}

To test the hypothesis that WM training would boost selective attention, processing speed and attention shifting, we conducted a third repeated-measures ANOVA on the composite T1, T2 and T3 attention scores; this revealed a significant effect of training, with a large effect size, $F(1$, $25)=442.31, p<0.001$, Cohen's $f=4.04$. As such, we employed a series of repeated-measures ANOVAs, detailed in Table 6, to test specific effects. All measures showed a significant decrease in reaction time between $\mathrm{T} 1$ and $\mathrm{T} 2$, revealing faster processing. The largest effect was observed for the most demanding task, the Opposite World task, which required the participant to inhibit a prepotent response.

\section{Long-Term Effects}

Of the original sample of 30, 26 children with ASD were retested at $\mathrm{T} 3$, three months after the posttest. Repeated measures ANOVAs with time (T1, T2, T3) as a within-subjects factor revealed significant main effects of time were observed for each of the WM tasks; see Table 5. Post-hoc Tukey's HSD tests explored the periods for which significant change occurred. Performance at T3 was significantly better than $\mathrm{T} 1$ for the three simple-spans tasks (forward digit span, nonword repetition and serial order word span), but not for the two complex-span tasks. Comparisons of T2 and T3 showed no significant changes except in backward digit recall which showed a significant decrease (e.g., worse performance). Figure 2 illustrates these results for the serial order word span (2a) and forward digit recall (2b), which followed the predicted pattern of significant improvements between $\mathrm{T} 1$ and $\mathrm{T} 2$ and between $\mathrm{T} 1$ and $\mathrm{T} 3$ and no change between T2 and T3. Performance on the backward digit recall task (2b), however, decreased significantly from T2 to T3.

The long-term stability of transfer effects was calculated for those measures of syntax and attention for which a significant T1-T2 increase was observed. As indicated in Table 6, the gains in syntactic abilities observed at T2 were still present at T3, with no significant decrement in performance. This pattern held for both syntactic measures 
Table 6 Repeated-measures ANOVA on syntax and attention

\begin{tabular}{|c|c|c|c|c|c|c|c|c|c|}
\hline \multirow[b]{3}{*}{$\mathrm{N}$ participants } & & \multirow{2}{*}{$\begin{array}{l}\text { Pretest T1 } \\
\mathrm{M}(\mathrm{SD})\end{array}$} & \multirow{2}{*}{$\begin{array}{l}\text { Posttest T2 } \\
\mathrm{M}(\mathrm{SD})\end{array}$} & \multirow{2}{*}{$\begin{array}{l}\text { T1-T2 Effect of } \\
\text { Time }\end{array}$} & \multirow{2}{*}{$\begin{array}{l}\text { Posttest T3 } \\
\text { M (SD) }\end{array}$} & \multirow{2}{*}{$\begin{array}{l}\text { T1-T2-T3 Effect } \\
\text { of Time }\end{array}$} & \multicolumn{3}{|c|}{ Post hoc HSD } \\
\hline & & & & & & & $\mathrm{T} 1-\mathrm{T} 2$ & T1-T3 & $\mathrm{T} 2-\mathrm{T} 3$ \\
\hline & & 30 & & & 26 & & & & \\
\hline \multirow[t]{3}{*}{$\begin{array}{l}\text { Elicited produc- } \\
\text { tion }\end{array}$} & $\begin{array}{l}\mathrm{N} \text { correct root } \\
\text { questions } \\
(\max =12)\end{array}$ & $6.8(4.1)$ & $7.9(3.2)$ & $\begin{array}{l}F(1,29)=5.64 \\
p=.02, \eta^{2}=.16\end{array}$ & $7.7(3.9)$ & $\begin{array}{c}F(2,50)=5.95 \\
p=.005 \\
\eta^{2}=.20\end{array}$ & $p=.006$ & $p=.03$ & $p=.8$ \\
\hline & $\begin{array}{l}\mathrm{N} w h \text {-fronted } \\
\text { object ques- } \\
\text { tions } \\
(\max =9)\end{array}$ & $3.2(2.6)$ & $3.5(2.8)$ & $\begin{array}{l}F(1,29)=0.41, \\
p=.52\end{array}$ & & & & & \\
\hline & $\begin{array}{l}\text { N correct clitics } \\
(\max =12)\end{array}$ & $2.8(3.6)$ & $3.2(3.5)$ & $\begin{array}{l}F(1,29)=1.43, \\
p=.24\end{array}$ & & & & & \\
\hline \multirow[t]{3}{*}{$\begin{array}{l}\text { Complex sen- } \\
\text { tence repetition }\end{array}$} & $\begin{array}{l}\text { N correct syl- } \\
\text { lables } \\
(\max =210)\end{array}$ & $119.1(44.9)$ & $138.1(39.2)$ & $\begin{array}{l}F(1,29)=15.82 \\
p<.001, \eta^{2} \\
\quad=.35\end{array}$ & $134.2(35.1)$ & $\begin{array}{c}F(2,50)=11.5 \\
p<.001 \\
\eta^{2}=.31\end{array}$ & $p<.001$ & $p=.003$ & $p=.5$ \\
\hline & $\begin{array}{l}\mathrm{N} \text { target structure } \\
(\max =15)\end{array}$ & $4.5(3.8)$ & $5.3(4.3)$ & $\begin{array}{l}F(1,29)=2.27 \\
p=.14\end{array}$ & & & & & \\
\hline & $\begin{array}{l}\text { N degree of } \\
\text { embedding } \\
(\max =15)\end{array}$ & $3.5(3.5)$ & $4.4(3.7)$ & $\begin{array}{l}F(1,29)=4.55 \\
p=.04, \eta^{2}=.14\end{array}$ & $4.2(3.5)$ & $\begin{array}{l}F(2,50)=2.72 \\
p=.07 \\
\eta^{2}=.10\end{array}$ & $p=0.08$ & $p=.2$ & $p=.9$ \\
\hline $\begin{array}{l}\text { Complement } \\
\text { sentence com- } \\
\text { prehension }\end{array}$ & $\begin{array}{l}N \text { correct } \\
\text { responses } \\
(\max =12)\end{array}$ & $7.4(2.4)$ & $8.3(2.5)$ & $\begin{array}{l}F(1,29)=9.13 \\
p=.005, \eta^{2}= \\
.24\end{array}$ & $7.9(2.8)$ & $\begin{array}{l}F(2,50)=2.07 \\
\quad p=.14 \\
\eta^{2}=.08\end{array}$ & $p=.1$ & $p=.5$ & $p=.7$ \\
\hline \multirow[t]{2}{*}{$\begin{array}{l}\text { Selective atten- } \\
\text { tion }\end{array}$} & Speed (ms) & $9.2(4.2)$ & $7.3(4.3)$ & $\begin{array}{l}F(1,29)=6.04 \\
p=.02, \eta^{2}=.17\end{array}$ & $7.5(3.7)$ & $\begin{array}{c}F(2,50)=6.05 \\
p=.004 \\
\eta^{2}=.19\end{array}$ & $p=.005$ & $p=.03$ & $p=.8$ \\
\hline & $\begin{array}{l}\text { Accuracy } \\
\quad(\max =20)\end{array}$ & $15.9(3.9)$ & $14.8(4.6)$ & $\begin{array}{l}F(1,29)=1.98, \\
p=.17\end{array}$ & & & & & \\
\hline Processing speed & Speed (ms) & $34.4(11.9)$ & $30.3(9.3)$ & $\begin{array}{l}F(1,29)=9.57 \\
p=.004, \eta^{2}= \\
\quad .25\end{array}$ & $29.9(7.6)$ & $\begin{array}{c}F(2,50)=8.45 \\
p<.001 \\
\eta^{2}=.25\end{array}$ & $p=.008$ & $p<.001$ & $p=.7$ \\
\hline $\begin{array}{l}\text { Attention shift- } \\
\text { ing }\end{array}$ & Speed (ms) & $48.2(20.4)$ & $39.4(15.2)$ & $\begin{array}{c}F(1,29)=17.21 \\
p<.001, \eta^{2} \\
\quad=.37\end{array}$ & $36.5(10.2)$ & $\begin{array}{c}F(2,50)=16 \\
p<.001 \\
\eta^{2}=.39\end{array}$ & $p<.001$ & $p<.001$ & $p=.7$ \\
\hline
\end{tabular}

Notations in bold indicate statistically significant results

T3 data include only 26 out of 30 participants, four children having not been retested due to the coronavirus COVID-19 pandemic

(elicited production of root questions, sentence repetition, see Fig. 2c) and for each of the three attentional tasks (2d).

\section{Further Analyses}

The results revealed a significant impact of WM training on WM itself (direct effects) and on attention and syntax (transfer effects); improvements in the latter were in the moderate range. Given the heterogenous nature of ASD, it was important to test whether improvements were observed for all participants. We calculated gains for the primary measures ${ }^{4}$ by subtracting

${ }^{4}$ For WM: Forward digit recall, nonword repetition, serial order word span, backward digit recall, counting span. For syntax: root questions and clitics, complex sentence repetition (correct syllables and embedding), and sentence comprehension. For attention: selective attention, processing speed and attention shifting. the $\mathrm{T} 2$ results from $\mathrm{T} 1$ results for each child. Appendix E presents these measures of gains for each child as well as group means for each measure. As expected, improvements were extremely variable with some children making progress on all the tasks (such as participants 4 or 30) and others showing no real improvement on any task (such as participants 17 or 20). We tested whether age, non-verbal reasoning, or autistic symptomatology predicted gains, using correlational analyses; none were significant, all $p$ 's $>0.10$.

\section{Discussion}

Our study explored the effects of an intensive WM training program, Magic Memory (Delage et al., 2017), on WM, syntax and attention, for 30 French-speaking children with 
a Serial order word span accuracy (/81)

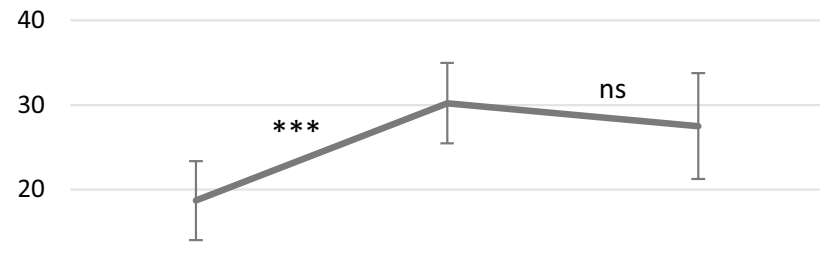

10

0

$\mathrm{T} 1$

c Sentence repetition accuracy

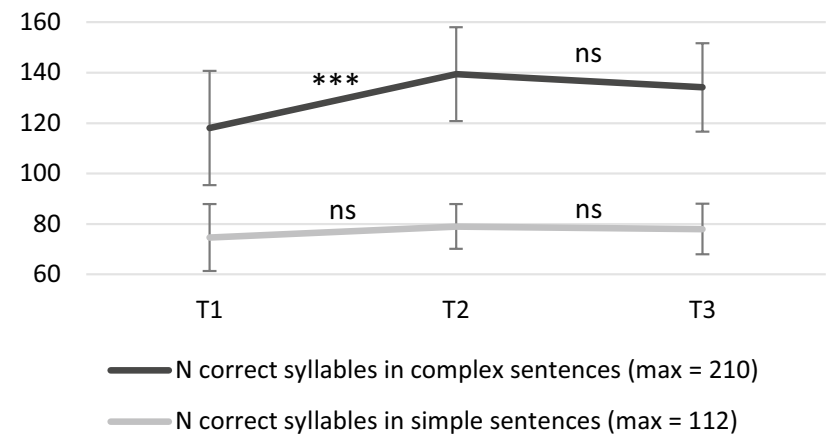

b Digit recall accuracy $(/ 16)$

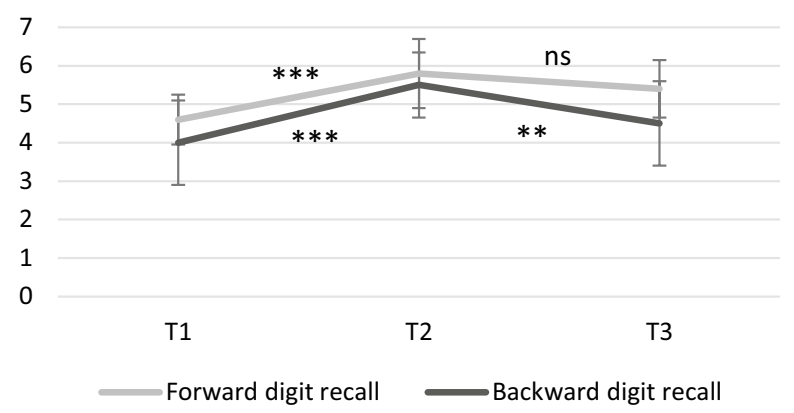

d Attentional tasks: Speed

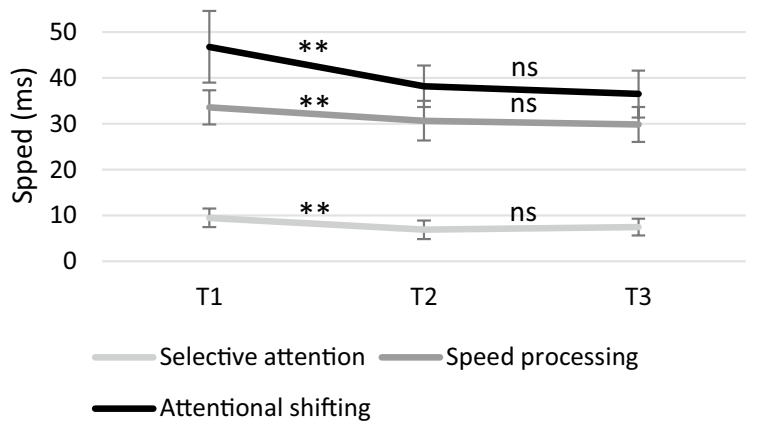

Notes. ${ }^{* * *}: \mathrm{p}<.001 ; * *: \mathrm{p}<.01 ; \mathrm{ns}=$ not significant

Fig. 2 T1, T2 and T3 performance for serial order word span and digit recall tasks, sentence repetition and attentional tasks

ASD aged 5;11 to $11 ; 10$. We expected similar results in ASD as those previously reported for similarly-aged children with DLD, namely, direct effects on WM as well as transfer effects on expressive syntax (Delage et al., 2020, 2021; Stanford et al., 2019). In the present work, we aimed to replicate and expand upon our previous studies with participants with DLD, and related studies reporting WM/syntax links in ASD (Durrleman \& Delage, 2016; Riches et al., 2010; Schuh \& Eigsti, 2012; Weismer et al., 2017). The current study employed measures used in previous training studies in DLD, along with several additional tasks:

i. An assessment of the comprehension of complement sentences;

ii. Tasks assessing selective attention, speeded processing and attentional shifting;

iii. Delayed post-tests three months after training, to test for long-term effects.

We predicted improved performance on the capacities directly trained, i.e. on WM, as well as on syntactic and attention domains not directly trained but hypothesized to be related to WM. We also predicted that these gains would be maintained three months after training.

\section{Links Between WM and Complex Syntax}

Preliminary analyses confirmed the close relation between complex-span measures (i.e., complex WM) and all measures of syntax in our participants with ASD, replicating previous results (Durrleman \& Delage, 2016; Riches et al., 2010; Weismer et al., 2017). The fact that simple spans did not appear to be linked to the same extent to syntactic capacities in our population suggests that the more executive component of WM plays a role in complex syntactic processing in ASD. This result echoes findings of Delage and Frauenfelder (2019) who reported that complex spans (but not simple ones) predicted measures of syntactic complexity in spontaneous language samples of $48 \mathrm{TD}$ children; this pattern was reversed in DLD (Delage \& Frauenfelder, 2020). This larger pattern of results suggests that the WM deficits in DLD reflect reduced phonological storage (see also Alt, 2011; Gathercole \& Baddeley, 1990), whereas the WM deficits in ASD reflect executive dysfunction, notably in mental flexibility (Demetriou et al., 2018). The current results are consistent with this hypothesis, as our participants with ASD had significantly better simple-span results (mean Z-score of - 1.2) relative to complex-span ones (mean Z-score of -2.5 ). Their difficulties in processing complex sentences 
likely reflect inefficient or otherwise more impaired performance of the cognitive operations required for complex spans (i.e., reduced cognitive flexibility to cope with interference during verbal storage).

\section{Direct Effects of WM Training}

The WM training was effective as it led to significant improvements in performance on all WM tasks. Admittedly, these tasks closely resembled the activities presented in the Magic Memory program, with distinct visual and verbal content and a distinct format (paper versus computerized). Nevertheless, such direct effects have not been consistently observed (Majerus, 2016; Melby-Lervag \& Hulme, 2013) and it was encouraging to see that the children were able to transfer their skill from one format to another.

Effect sizes were impressive, with medium to large effects, with the exception of non-word repetition, for which improvements were significant with a small effect size. Speech-sound difficulties have been reported for subgroups of children with ASD (Kjelgaard \& Tager-Flusberg, 2001; Wolk et al., 2016; Zebib et al., 2013), and such difficulties may have obscured the training effects. The serial-orderword-span task, in contrast, displayed the highest effect size. This task of putting animal cards on a podium in order is very similar to the training program's task of putting pictures corresponding to familiar words into train cars in order, similarity that undoubtedly contributed to the large gains that participants displayed in this particular task. In addition, this serial memory task requires participants to remember the order of animals participating in the race, without necessarily retaining phonological representations of the animals' names (Majerus, 2008; Majerus et al., 2006). Thus, this task focuses on WM while minimizing the influence of language, and of potentially degraded phonological representations. The finding that the task that least depends on phonological representations showed the most pronounced training effects is consistent with the aims of the training, which is meant to enhance "pure" memory processes (while also utilizing verbal material). These results suggest that this program will be effective for other conditions characterized by phonological deficits, including some forms of ASD and children with speech-sound disorders (Claessen \& Leitão, 2012; Gathercole \& Baddeley, 1990; Leonard, 2014; Zebib et al., 2013).

\section{Transfer Effects of WM Training on Syntax}

All syntactic measures, both expressive and receptive, showed a mean increase in accuracy, with significant improvement in the production of root questions, and in the repetition and comprehension of complex sentences. Such transfer effects cannot be attributed to the material used in training, since the WM program presented only isolated words. Results of the sentence repetition in particular were striking, because they suggested significant increases at post-test for complex but not for simple sentences, though both types of sentences were matched in length. Similarly, independent of sentence length, participants showed improvement in producing complex sentential embedding.

Taken together, these exciting results suggest a meaningful transfer of WM improvement into the domain of complex expressive syntax, extending previous findings of training effects for children with DLD (Delage et al., 2021). Not all of the previous DLD results were replicated here; for example, there was no significant improvement in the production of accusative clitics (Stanford et al., 2019). Differences between response patterns in DLD and ASD likely reflect the nature of the tasks and the deficits specific to the autistic spectrum. For example, sentence repetition task involves limited social interaction; participants simply repeat the target sentence. In contrast, the clitic production task, which is understood by age four in typical development (Delage et al., 2016), requires more direct interaction with the experimenter, who asks questions (ex: Look! What is the man doing with his car? Tell me!) about pictured scenes. While the social demands are highly structured and relatively small, participants must listen and respond to the examiners; this could be a more difficult task for children with ASD (DSM-5, APA, 2013). However, the current results were not consistent with this hypothesis, as there was no relationship between syntax scores and autistic symptomatology (CARS scores). A more detailed assessment of the social communication skills, using the Children's Communication Checklist (CCC-2, Bishop, 2003) for example, might have been more sensitive to individual differences in pragmatics.

Results also showed significant improvements in the comprehension of complement sentences. Receptive skills were not assessed in our training studies of children with DLD, who do display deficits in receptive syntax (Delage \& Frauenfelder, 2020; Friedman \& Novrogrodsky, 2004). Such receptive difficulties are widely reported in children with ASD, including deficits in the comprehension of complex $w h$-questions and relative clauses (Durrleman et al., 2016), passives (Durrleman et al., 2017), clitics (Terzi et al., 2014), and more globally on standardized measures of receptive syntax and morphology (Brynskov et al., 2017). Difficulties in comprehension of object relatives have been found to persist in young adults (Durrleman et al., 2015). In 2019, Durrleman et al. showed that comprehension of complement sentences can be improved in children with ASD, aged 5 to 11, through a brief training targeting sentential complements. In this study, WM training provided benefits in both cognitive and linguistic domains. Future work could compare the effects of training on complex syntax (as in Durrleman et al., 2019) to 
effects of WM training, in order to test whether effects are bidirectional. Such studies will illuminate language and cognitive deficits in this population.

\section{Transfer Effects of WM Training on Attention}

In addition to the direct effect on WM capacities, WM training had an indirect effect on other attentional abilities, which is unsurprising given their theoretical overlap (Baddeley, 2003; Barrouillet \& Camos, 2012; Engle, 2002; Majerus et al., 2009; Veer et al., 2017). Indeed, participants showed improved speed with no concomitant decrease in accuracy for the three aspects of attention: selective attention, processing speed and attention shifting. These gains suggest that WM training provides a cognitive "boost," allowing children to process information more quickly, thereby freeing up processing resources. This change likely has a snowballing or cascading effect on syntactic processing as the reduction of cognitive limitations would influence the processing of computationally complex structures, such as those including embedding and/or a movement operation (Delage \& Frauenfelder, 2019, 2020; Jakubowicz \& Strik, 2008; Tuller et al., 2012). Attention limitations are also considered by Chomsky (2005) to impact the processing of syntax, and attention is seen as underlying the development of executive functions, such as WM and inhibition (Garon et al., 2008); given this foundation, we hypothesized that training in WM could lead to improvements on both attentional and syntactic measures.

Although previous WM training studies conducted with children with DLD have found the same direct and indirect effects (on syntax), these studies did not assess attentional abilities and were therefore unable to test for the transfer effects on attentional tasks that we obtained in the current study. Future studies should also evaluate these transfer effects in children with DLD. Similar effects would be expected, consistent with studies linking attentional resources to the processing of complex syntax in children with DLD (Montgomery et al., 2009; Stanford \& Delage, 2020). Moreover, it would be informative to contrast effects of pure training of the attentional component (such as the TALI, Kirk et al., 2016) with effects in the current study, and to compare effects of both on syntax; this would reveal whether linguistic gains following intensive WM training can be attributed to WM improvements or to better functioning of the attentional system.

\section{Follow-Up}

Almost all participants (26/30) were retested three months after training to assess long-term effects. Results showed that improvements were maintained in all WM tasks except backward digit recall, for which performance decreased from T2 to T3 (although T3 performance was still significantly better than at baseline). This task requires reversing the order of previously heard stimuli (digits). The training program was similar, but involving color names rather than digits. It is possible that the extensive overlap between tasks boosted the progress observed between $\mathrm{T} 1$ and $\mathrm{T} 2$, and that these gains were not maintained without practice (see Fig. 2b). Aside from this task, the overall results point in the direction of an encouragingly persistent and long-term improvement in WM performance, in contrast to previous WM training studies with healthy adults (Melby-Lervag \& Hulme, 2013; Melby-Lervag et al., 2016). This suggests that WM training might be most effective with children, whose development is ongoing, or for individuals with specific WM deficits.

Long-term transfer effects were similarly positive, with improvements maintained on all measures showing $\mathrm{T} 1$ to $\mathrm{T} 2$ gains, whether in the areas of syntax or attentional skills. This result is particularly promising since we were unable to demonstrate maintenance of syntactic transfer effects in previous work, likely because only a small subset of children with DLD were retested (12 out of 32; Delage et al., 2021).

\section{Limitations}

The present study did not include an active control group, which would have conclusively demonstrated that, without specific training, the performance in WM, syntax and attention would show significantly fewer improvements. As discussed above, we chose not to include such a group because our previous studies of children with DLD or TD revealed no benefit to WM or syntax from training focusing on academic skills (Delage et al., 2021; Stanford et al., 2019). While this is a significant limitation, we argue that the T2-T3 comparison provides a type of control, in line with ABAB treatment paradigms (e.g., Kratochwill et al., 2013). Such studies involve alternation between a baseline period (A) and a treatment period (B), sometimes including only a single subject. In such paradigms, the specific effects of the program should be visible following the training periods (B) and more discrete following the non-active (baseline) periods (A). This was precisely the pattern observed in the current study, in which the children's performance did not improve between $\mathrm{T} 2$ and $\mathrm{T} 3$, suggesting that the progress observed from $\mathrm{T} 1$ to $\mathrm{T} 2$ was a function of the training program, rather than general maturation and development.

We also acknowledge that transfer effects from WM training onto syntax could be explained by other reasons than attentional resources and computational processing. Indeed, training sessions involve interactions between the child and the caregiver, as well as the experimenter. The increase in conversations with this diversity of interlocutors may also have helped to motivate children with ASD to engage in language tasks. In order to explore this aspect, it would have been useful to administer a questionnaire on the children's social interactions, such as the Social Communication 
Questionnaire (Rutter et al., 2003a, 2003b), before and after the training. We leave this for future work. Other limitations stem from the fact that we did not evaluate the capacities of children to generalize their apparently improved syntactic skills to other daily life contexts, which would have been possible if we had carried out an analysis of spontaneous language. Complex syntax, assessed by such an analysis of spontaneous language samples, has already been shown to be strongly linked to WM in children with TD and DLD (Delage \& Frauenfelder, 2019, 2020). We would thus expect that our training would also improve the children's spontaneous syntax, yielding richer productions in conversational contexts. Moreover, it should be noted that our protocol was the same for all children, whereas the symptoms/traits of ASD are known to be heterogenous in nature. Adapting the material and the setting to the particularities of each child would certainly be useful in clinical practice, but this would not be suitable for a rigorous experimental design.

We should finally note that our statistical approach involved starting with an omnibus test of change in broad cognitive domains, with significant results to be followed by detailed exploratory tests of change in specific local task domains. While our results are compelling, and seem to be highly consistent across within-domain measures, this approach requires further replication given the relatively small sample size and the number of comparisons.

\section{Conclusion}

Following WM training, our participants showed improvements not only in WM but also in distal domains such as speed of attentional processing and expressive and receptive syntax. Of course, these changes might reflect a general g-factor, such that the children with stronger cognitive abilities pay more attention in the training and show the greatest improvements. To address this possibility, future work could include a dynamic measure of cognitive functioning to directly examine the child's response to learning (Camilleri \& Law, 2007). Dynamic assessment of learning capacity provides a reliable and valid measure of general intellectual functioning and is a good predictor of future learning (Hessels \& Hessels-Schlatter, 2010). Moreover, this type of assessment would be highly appropriate for children with emotional or personality challenges that could interfere with their performance (Tzuriel, 2001). A dynamic assessment could illuminate the inter-subject variability we observed in this study, with ASD participants who benefit more from WM training being those who show the better capacity to learn.

While they must be replicated, these exciting results provide impetus for further studies of WM interventions. Thereafter, the training materials should be available to children with WM or syntactic impairments, regardless of the proximal source of those impairments (e.g., DLD or ASD).
Findings of this study provide further evidence in support of the efficacy of WM training in multiple domains, and fall within an 'evidence-based practice' framework, which emphasizes the role of research findings in clinical decisionmaking (Sackett et al., 2000).

Supplementary Information The online version contains supplementary material available at https://doi.org/10.1007/s10803-021-05295-z.

Acknowledgements This study was supported by Swiss National Science Foundation Grant 100014_159606 (awarded to Hélène Delage)

Author Contributions All authors contributed to the study conception and design. Material preparation, data collection and analysis were performed by Hélène Delage, Inge-Marie Eigsti and Emily Stanford. The first draft of the manuscript was written by Hélène Delage and all authors commented on previous versions of the manuscript. All authors read and approved the final manuscript.

Funding Open Access funding provided by Université de Genève.

\section{Declarations}

Conflict of interest There are no real or potential conflicts of interest related to the manuscript.

Open Access This article is licensed under a Creative Commons Attribution 4.0 International License, which permits use, sharing, adaptation, distribution and reproduction in any medium or format, as long as you give appropriate credit to the original author(s) and the source, provide a link to the Creative Commons licence, and indicate if changes were made. The images or other third party material in this article are included in the article's Creative Commons licence, unless indicated otherwise in a credit line to the material. If material is not included in the article's Creative Commons licence and your intended use is not permitted by statutory regulation or exceeds the permitted use, you will need to obtain permission directly from the copyright holder. To view a copy of this licence, visit http://creativecommons.org/licenses/by/4.0/.

\section{References}

Adams, A. M., \& Gathercole, S. E. (2000). Limitations in working memory: Implications for language development. International Journal of Language and Communication Disorders, 35(1), 95-117. https://doi.org/10.1080/136828200247278

Alloway, T. P. (2018). Working memory and clinical developmental disorders: Theories, debates and interventions. Routledge.

Alloway, T. P., Rajendran, G., \& Archibald, L. M. D. (2009). Working memory in children with developmental disorders. Journal of Learning Disabilities, 42, 372-382.

Alloway, T. P., Seed, T., \& Tewolde, F. (2016). An investigation of cognitive overlap in working memory profiles in children with developmental disorders. International Journal of Educational Research, 75, 1-6. https://doi.org/10.1016/j.ijer.2015.09.009

Alt, M. (2011). Phonological working memory impairments in children with specific language impairment: Where does the problem lie? Journal of Communication Disorders, 44(2), 173-185. https:// doi.org/10.1016/j.jcomdis.2010.09.003

Ambridge, B., Bidgoof, A., \& Thomas, K. (2021). Disentangling syntactic, semantic and pragmatic impairments in ASD: Elicited 
production of passives. Journal of Child Language, 48(1), 184201. https://doi.org/10.1017/S0305000920000215

American Psychiatric Association. (2013). Diagnostic and statistical manual of mental disorders (5th ed.). American Psychiatric Association Publishing.

Baddeley, A. D. (2003). Working memory and language: An overview. Journal of Communication Disorders, 36(3), 189-208. https:// doi.org/10.1016/S0021-9924(03)00019-4

Baron-Cohen, S., Leslie, A. M., \& Frith, U. (1985). Does the autistic child have a "theory of mind?" Cognition, 21(1), 37-46. https:// doi.org/10.1016/0010-0277(85)90022-8

Barouillet, P., \& Camos, V. (2007). Le développement de la mémoire de travail. In J. Lautrey (Ed.), Psychologie du développement et de l'éducation (pp. 51-86). PUF.

Barrouillet, P., Bernardin, S., \& Camos, V. (2004). Time constraints and resource sharing in adults' working memory spans. Journal of Experimental Psychology: General, 133(1), 83. https://doi.org/ 10.1037/0096-3445.133.1.83

Barrouillet, P., \& Camos, V. (2012). As time goes by: Temporal constraints in working memory. Current Directions in Psychological Science, 21(6), 413-419. https://doi.org/10.1177/0963721412 459513

Bejarano-Martín, Á., Canal-Bedia, R., Magán-Maganto, M., Fernández-Álvarez, C., Lóa-Jónsdóttir, S., Saemundsen, E., ... Posada, M. (2020). Efficacy of focused social and communication intervention practices for young children with autism spectrum disorder: A meta-analysis. Early Childhood Research Quarterly, 51, 430-445. https://doi.org/10.1016/j.ecresq.2020.01.004

Bennetto, L., Pennington, B., \& Rogers, S. (1996). Intact and impaired memory functions in autism. Child Development, 67, 1816-1835. https://doi.org/10.2307/1131734

Bishop, D. V., Snowling, M. J., Thompson, P. A., Greenhalgh, T., Catalise-2 Consortium, Adams, C., ... Boyle, C. (2017). Phase 2 of CATALISE: A multinational and multidisciplinary Delphi consensus study of problems with language development: Terminology. Journal of Child Psychology and Psychiatry, 58(10), 1068-1080.https://doi.org/10.1111/jcpp.12721

Bishop, D. V. (2003). The children's communication checklist: CCC-2. Harcourt Assessment.

Bishop, D. V. (2010). Overlaps between autism and language impairment: Phenomimicry or shared etiology? Behavior Genetics, 40(5), 618-629.

Boutard, C., \& Gatignol, P. (2015). Mémoire de Travail. Ortho Editions.

Brynskov, C., Eigsti, I. M., Jørgensen, M., Lemcke, S., Bohn, O. S., \& Krøjgaard, P. (2017). Syntax and morphology in Danish-speaking children with autism spectrum disorder. Journal of Autism and Developmental Disorders, 47(2), 373-383. https://doi.org/ 10.1007/s10803-016-2962-7

Camilleri, B., \& Law, J. (2007). Assessing children referred to speech and language therapy: Static and dynamic assessment of receptive vocabulary. Advances in Speech-Language Pathology, 9(4), 323-331. https://doi.org/10.1080/14417040701624474

Case, R., Kurland, M., \& Goldberg, J. (1982). Operational efficiency and the growth of short-term memory. Journal of Experimental Child Psychology, 33, 386-404. https://doi.org/10.1016/00220965(82)90054-6

Centers for Disease Control and Prevention (CDC). (2016). Prevalence and characteristics of autism spectrum disorder among children aged 8 years-autism and developmental disabilities monitoring network, 11 sites, United States, 2012. Morbidity and Mortality Weekly Report. Surveillance Summaries (washington, DC: 2002), 65(3), 1-23.

Chomsky, N. (2005). Three factors in language design. Linguistic Inquiry, 36(1), 1-22. https://doi.org/10.1162/0024389052993655
Chien, Y. L., Gau, S. S. F., Chiu, Y. N., Tsai, W. C., Shang, C. Y., \& $\mathrm{Wu}, \mathrm{Y}$. Y. (2014). Impaired sustained attention, focused attention, and vigilance in youths with autistic disorder and Asperger's disorder. Research in Autism Spectrum Disorders, 8(7), 881-889. https://doi.org/10.1016/j.rasd.2014.04.006

Chien, Y. L., Gau, S. F., Shang, C. Y., Chiu, Y. N., Tsai, W. C., \& Wu, Y. Y. (2015). Visual memory and sustained attention impairment in youths with autism spectrum disorders. Psychological Medicine, 45(11), 2263-2273. https://doi.org/10.1017/S0033 291714003201

Claessen, M., \& Leitão, S. (2012). Phonological representations in children with SLI. Child Language Teaching and Therapy, 28(2), 211-223.

Cowan, N. (1999). An embedded-processes model of working memory. In A. Miyake \& P. Shah (Eds.), Models of working memory: Mechanisms of active maintenance and executive control (pp. 62-101). Cambridge University Press. https://doi.org/10.1017/ CBO9781139174909.006

De Abreu, P. M. J. E., Gathercole, S. E., \& Martin, R. (2011). Disentangling the relationship between working memory and language: The roles of short-term storage and cognitive control. Learning and Individual Differences, 21(5), 569-574. https://doi.org/10. 1016/j.lindif.2011.06.002

De Villiers, J. G., \& Pyers, J. E. (2002). Complements to cognition: A longitudinal study of the relationship between complex syntax and false-belief-understanding. Cognitive Development, 17(1), 1037-1060. https://doi.org/10.1016/S0885-2014(02)00073-4

Delage, H., Da Costa, J., \& Durrleman, S. (2017). Magic Memory. Experimental program. http://tecfa.unige.ch/proj/logo/Magic Memory.html

Delage, H., Stanford, E., Piller, A. G., \& Durrleman, S. (2020). Entraînement de la mémoire de travail : Quels effets sur la mémoire et la syntaxe d'enfants présentant un trouble développemental du langage ? Approche Neuropsychologique des Apprentissages chez l'Enfant, 166, 319-329.

Delage, H., Stanford, E., \& Durrleman, S. (2021). Working memory training enhances complex syntax in children with Developmental Language Disorder. Applied Psycholinguistics, 42(5), 1341-1375. https://doi.org/10.1017/S0142716421000369

Delage, H., Durrleman, S., \& Frauenfelder, U. H. (2016). Disentangling sources of difficulty associated with the acquisition of accusative clitics in French. Lingua, 180, 1-24. https://doi.org/10.1016/j. lingua.2016.03.005

Delage, H., \& Frauenfelder, U. H. (2019). Syntax and working memory in typically-developing children: Focus on syntactic complexity. Language, Interaction and Acquisition, 10(2), 141-176. https:// doi.org/10.1075/lia.18013.del

Delage, H., \& Frauenfelder, U. H. (2020). Relationship between working memory and complex syntax in children with Developmental Language Disorder. Journal of Child Language, 47(3), 600-632. https://doi.org/10.1017/S0305000919000722

Demetriou, E. A., Lampit, A., Quintana, D. S., Naismith, S. L., Song, Y. J. C., Pye, J. E., ... Guastella, A. J. (2018). Autism spectrum disorders: a meta-analysis of executive function. Molecular $p s y$ chiatry, 23(5), 1198-1204.https://doi.org/10.1038/mp.2017.75

Durrleman, S., Burnel, M., De Villiers, J. G., Thommen, E., Yan, R., \& Delage, H. (2019). The impact of grammar on mentalizing: A training study including children with autism spectrum disorder and developmental language disorder. Frontiers in Psychology, 10, 2478. https://doi.org/10.3389/fpsyg.2019.02478

Durrleman, S., \& Delage, H. (2016). Autism spectrum disorder and specific language impairment: Overlaps in syntactic profiles. Language Acquisition, 23, 361-386. https://doi.org/10.1080/ 10489223.2016.1179741 
Durrleman, S., Delage, H., Prévost, P., \& Tuller, L. (2017). The comprehension of passives in autism spectrum disorder. Glossa, 2, 1-30. https://doi.org/10.5334/gjgl.205

Durrleman, S., Hippolyte, L., Zufferey, S., Iglesias, K., \& Hadjikhani, N. (2015). Complex syntax in autism spectrum disorders: A study of relative clauses. International Journal of Language \& Communication Disorders, 50(2), 260-267. https://doi.org/10. 1111/1460-6984.12130

Durrleman, S., Marinis, T., \& Franck, J. (2016). Syntactic complexity in the comprehension of wh-questions and relative clauses in typical language development and autism. Applied Psycholinguistics, 37(6), 1501-1527. https://doi.org/10.1017/S014271641 6000059

Eigsti, I. M. (2009). Syntax and working memory in preschool children with autism. Lap Lambert Academic Pub.

Eigsti, I. M., Brooke de Marchena, A., Schuh, J., \& Kelley, E. A. (2011). Language acquisition in autism spectrum disorders: A developmental review. Research in Autism Spectrum Disorders, 5, 681-691. https://doi.org/10.1016/j.rasd.2010.09.001

Ellis Weismer, S., \& Thordardottir, E. T. (2002). Cognition and language. In P. Accardo, A. Capute, \& B. Rogers (Eds.), Disorders of language development (pp. 21-37). Timonium.

Engle, R. W. (2002). Working memory capacity as executive attention. Current Directions in Psychological Science, 11(1), 19-23.

Finney, M. C., Montgomery, J. W., Gillam, R. B., \& Evans, J. L. (2014). Role of working memory storage and attention focus switching in children's comprehension of spoken object relative sentences. Child Development Research. https://doi.org/10.1155/ 2014/450734

Friedmann, N., \& Novogrodsky, R. (2004). The acquisition of relative clause comprehension in Hebrew: A study of SLI and normal development. Journal of Child Language, 31, 661-681. https:// doi.org/10.1017/S0305000904006269

Frizelle, P., \& Fletcher, P. (2014). Relative clause constructions in children with specific language impairment. International Journal of Language \& Communication Disorders, 49(2), 255-264. https:// doi.org/10.1111/1460-6984.12070

Frizelle, P., \& Fletcher, P. (2015). The role of memory in processing relative clauses in children with specific language impairment. American Journal of Speech and Language Pathology, 24, 47-59. https://doi.org/10.1044/2014_AJSLP-13-0153

Frizelle, P., O’Neill, C., \& Bischop, D. V. M. (2017). Assessing understanding of relative clauses: A comparison of multiple-choice comprehension versus sentence repetition. Journal of Child Language, 44(6), 1435-1457. https://doi.org/10.1017/S030500091 6000635

Frye, D., Zelazo, P. D., \& Palfai, T. (1995). Theory of mind and rulebased reasoning. Cognitive Development, 10, 483-527. https:// doi.org/10.1016/0885-2014(95)90024-1

Gabig, C. S. (2008). Verbal working memory and story retelling in school-age children with autism. Language, Speech, and Hearing Services in Schools, 39(4), 498-511. https://doi.org/10.1044/ 0161-1461(2008/07-0023)

Garon, N., Bryson, S. E., \& Smith, I. M. (2008). Executive function in preschoolers: A review using an integrative framework. Psychological Bulletin, 134(1), 31. https://doi.org/10.1037/0033-2909. 134.1.31

Garretson, H. B., Fein, D., \& Waterhouse, L. (1990). Sustained attention in children with autism. Journal of Autism and Developmental Disorders, 20(1), 101-114. https://doi.org/10.1007/ BF02206860

Gathercole, S. E., \& Baddeley, A. (1990). Phonological memory deficits in language disordered children: Is there a causal connection? Journal of Memory and Language, 29, 336-360. https://doi.org/10.1016/0749-596X(90)90004-J
Habib, A., Harris, L., Pollick, F., \& Melville, C. (2019). A metaanalysis of working memory in individuals with autism spectrum disorders. PLOS ONE, 14(4), e0216198. https://doi.org/ 10.1371/journal.pone.0216198

Hessels, M., \& Hessels-Schlatter, C. (2010). L'apport des tests d'apprentissage dans l'évaluation des capacités intellectuelles des élèves avec difficultés scolaires. [The usefulness of learning tests for the evaluation of the intellectual capacities of children with learning difficulties]. In M. Hessels \& C. HesselsSchlatter (Eds.), Evaluation et intervention auprès d'élèves en difficultés [Assessment and intervention with children with difficulties] (pp. 5-34). Peter Lang.

Hill, T. L., Gray, S. A., Kamps, J. L., \& Varela, R. E. (2015). Age and adaptive functioning in children and adolescents with ASD: The effects of intellectual functioning and ASD symptom severity. Journal of Autism and Developmental Disorders, 45(12), 4074-4083. https://doi.org/10.1007/ s10803-015-2522-6

Ibbotson, P., \& Kearvell-White, J. (2015). Inhibitory control predicts grammatical ability. PLoS ONE, 10(12), e0145030. https://doi. org/10.1371/journal.pone.0145030

Im-Bolter, N., Johnson, J., \& Pascual-Leone, J. (2006). Processing limitations in children with specific language impairment: The role of executive function. Child Development, 77(6), 1822-1841. https://doi.org/10.1111/j.1467-8624.2006.00976.x

Jakubowicz, C. (2006). Protocole pour la compréhension des questions racines. Institut de psychologie. CNRS-FRE 2929, Université Paris V Descartes.

Jakubowicz, C. (2011). Measuring derivational complexity: New evidence from typically developing and SLI learners of L1 French. Lingua, 121(3), 339-351. https://doi.org/10.1016/j.lingua.2010. 10.006

Jakubowicz, C., \& Strik, N. (2008). Scope-marking strategies in the acquisition of long distance wh-questions in French and Dutch. Language and Speech, 51(1-2), 101-132.

Johnson, K. A., Robertson, I. H., Kelly, S. P., Silk, T. J., Barry, E., Dáibhis, A., ... Gill, M. (2007). Dissociation in performance of children with ADHD and high-functioning autism on a task of sustained attention. Neuropsychologia, 45(10), 22342245.https://doi.org/10.1016/j.neuropsychologia.2007.02.019

Joseph, R. M., Steele, S. D., Meyer, E., \& Tager-Flusberg, H. (2005). Self-ordered pointing in children with autism: Failure to use verbal mediation in the service of working memory? Neuropsychologia, 43(10), 1400-1411. https://doi.org/10.1016/j.neuropsych ologia.2005.01.010

Kapa, L. L., \& Plante, E. (2015). Executive function in SLI: Recent advances and future directions. Current Developmental Disorders Reports, 2(3), 245-252. https://doi.org/10.1007/ s40474-015-0050-x

Khomsi, A., Khomsi, J., Parbeau-Guéno, A., \& Pasquet, F. (2007). Bilan informatisé de langage oral au Cycle III et au collège (BILO3C). ECPA.

Kimhi, Y. (2014). Theory of mind abilities and deficits in autism spectrum disorders. Topics in Language Disorders, 34(4), 329-343. https://doi.org/10.1097/TLD.0000000000000033

Kirk, H. E., Gray, K. M., Ellis, K., Taffe, J., \& Cornish, K. M. (2016). Computerised attention training for children with intellectual and developmental disabilities: A randomised controlled trial. Journal of Child Psychology and Psychiatry, 57(12), 1380-1389. https://doi.org/10.1111/jcpp.12615

Kjelgaard, M. M., \& Tager-Flusberg, H. (2001). An investigation of language impairment in autism: Implications for genetic subgroups. Language and Cognitive Processes, 16, 287-308. https:// doi.org/10.1080/01690960042000058

Kratochwill, T. R., Hitchcock, J. H., Horner, R. H., Levin, J. R., Odom, S. L., Rindskopf, D. M., \& Shadish, W. R. (2013). Single-case 
intervention research design standards. Remedial and Special Education, 34(1), 26-38.

Leonard, L. B. (2014). Specific language impairment across languages. Child Development Perspectives, 8(1), 1-5. https://doi.org/10. 1111/cdep. 12053

Lim, P. (2018). Specific language impairment in children with highfunctioning autism spectrum disorder. Inquiries Journal, 10(05), 1.

Lord, C., Rutter, M., DiLavore, P. C., \& Risi, S. (2002). Autism diagnostic observation (ADOS) manual. Los Angeles: Western Psychological Services. (French Adaptation: Rogé, B. et al., 2015, Paris: Editions Hogrefe).

Majerus, S. (2008). La mémoire verbale à court terme: Un simple produit des interactions entre systèmes langagiers, attentionnels et de traitement de l'ordre sériel ? Psychologie Française, 53(3), 327-341. https://doi.org/10.1016/j.psfr.2008.02.001

Majerus, S. (2016). Optimisation et rééducation de la mémoire de travail : Une synthèse critique. Approche Neuropsychologique Des Apprentissages chez L'enfant, 141, 167-174.

Majerus, S., Heiligenstein, L., Gautherot, N., Poncelet, M., \& Van der Linden, M. (2009). Impact of auditory selective attention on verbal short-term memory and vocabulary development. Journal of Experimental Child Psychology, 103(1), 66-86. https://doi.org/ 10.1016/j.jecp.2008.07.004

Majerus, S., Poncelet, M., Greffe, C., \& Van der Linden, M. (2006). Relations between vocabulary development and verbal shortterm memory: The relative importance of short-term memory for serial order and item information. Journal of Experimental Child Psychology, 93, 95-119. https://doi.org/10.1016/j.jecp. 2005.07.005

Manly, T., Robertson, I. H., Anderson, V., \& Nimmo-Smith, I. (1999). The test of everyday attention for children (TEA-CH). Thames Valley Test Company.

Manly, T., Robertson, I. H., Anderson, V., Nimmo-Smith, I., Lussier, F., \& Flessas, J. (2006). TEA-Ch: Test d'Evaluation de l'Attention Chez l'enfant. Éditions du Centre de psychologie appliquée (ECPA).

McCrimmon, A. W., Matchullis, R. L., Altomare, A. A., \& SmithDemers, A. D. (2016). Executive functions in autism spectrum disorder. Handbook of assessment and diagnosis of autism spectrum disorder (pp. 403-425). Springer. https://doi.org/10.1007/ 978-3-319-27171-2_21

Melby-Lervag, M., \& Hulme, C. (2013). Is working memory training effective? A meta-analytic review. Developmental Psychology, 49(2), 270-291. https://doi.org/10.1037/a0028228

Melby-Lervag, M., Redick, T. S., \& Hulme, C. (2016). Working memory training does not improve performance on measures of intelligence or other measures of "far transfer" evidence from a meta-analytic review. Perspectives on Psychological Science, $11(4), 512-534$.

Miyake, A., Friedman, N. P., Emerson, M. J., Witzki, A. H., Howerter, A., \& Wager, T. D. (2000). The unity and diversity of executive functions and their contributions to complex "Frontal Lobe" tasks: A latent variable analysis. Cognitive Psychology, 41(1), 49-100. https://doi.org/10.1006/cogp.1999.0734

Modyanova, N., Perovic, A., \& Wexler, K. (2017). Grammar is differentially impaired in subgroups of autism spectrum disorders: Evidence from an investigation of tense marking and morphosyntax. Frontiers in Psychology, 8, 320. https://doi.org/10.3389/ fpsyg.2017.00320

Montgomery, J. W. (2008). Role of auditory attention in the real-time processing of simple grammar by children with specific language impairment: A preliminary investigation. International Journal of Language \& Communication Disorders, 43(5), 499-527. https://doi.org/10.1080/13682820701736638
Montgomery, J. W., \& Evans, J. L. (2009). Complex sentence comprehension and working memory in children with specific language impairment. Journal of Speech Language and Hearing Research, 52(2), 269-288. https://doi.org/10.1044/10924388(2008/07-0116)

Montgomery, J. W., Evans, J. L., \& Gillam, R. B. (2009). Relation of auditory attention and complex sentence comprehension in children with specific language impairment: A preliminary study. Applied Psycholinguistics, 30(1), 123. https://doi.org/ 10.1017/S0142716408090061

Montgomery, J., Magimairaj, B., \& O’Malley, M. (2008). Role of working memory in typically developing children's complex sentence comprehension. Journal of Psycholinguistic Research, 37(5), 331-354. https://doi.org/10.1007/s10936-008-9077-z

Mousty, P., Leybaert, J., Alegria, J., Content, A., \& Moraïs, J. (1994). B.E.L.E.C.: Batterie d'évaluation du langage et de ses troubles. Laboratoire de psychologie.

Noterdaeme, M., Amorosa, H., Mildenberger, K., Sitter, S., \& Minow, F. (2001). Evaluation of attention problems in children with autism and children with a specific language disorder. European Child \& Adolescent Psychiatry, 10(1), 58-66. https://doi.org/10.1007/s007870170048

Oi, M. (2008). Using question words or asking yes/no questions: Failure and success in clarifying the intentions of a boy with high-functioning autism. Clinical Linguistics and Phonetics, 22, 814-823. https://doi.org/10.1080/02699200802130821

Oi, M. (2010). Do Japanese children with high-functioning autism spectrum disorder respond differently to Wh-questions and Yes/No-questions? Clinical Linguistics and Phonetics, 24, 691-705. https://doi.org/10.3109/02699206.2010.488313

Prévost, P., Tuller, L., Barthez, M. A., Malvy, J., \& Bonnet-Brilhault, F. (2017). Production and comprehension of French wh-questions by children with autism spectrum disorder: A comparative study with specific language impairment. Applied Psycholinguistics, 38(5), 1095. https://doi.org/10.1017/S0142 716417000078

Prévost, P., Tuller, L., Zebib, R., Barthez, M. A., Malvy, J., \& BonnetBrilhault, F. (2018). Pragmatic versus structural difficulties in the production of pronominal clitics in French-speaking children with autism spectrum disorder. Autism \& Developmental Language Impairments. https://doi.org/10.1177/2396941518799643

Raven, J. C., \& Court, J. H. (1998). Raven's progressive matrices and vocabulary scales. Cham: Oxford psychologists Press.

Redick, T. S., \& Lindsey, D. R. (2013). Complex span and n-back measures of working memory: A meta-analysis. Psychonomic Bulletin \& Review, 20(6), 1102-1113. https://doi.org/10.3758/ s13423-013-0453-9

Riches, N. G., Loucas, T., Baird, G., Charman, T., \& Simonoff, E. (2010). Sentence repetition in adolescents with specific language impairments and autism: An investigation of complex syntax. International Journal of Language \& Communication Disorders, 45(1), 47-60. https://doi.org/10.3109/13682820802647676

Roberts, J. A., Rice, M. L., \& Tager-Flusberg, H. (2004). Tense marking in children with autism. Applied Psycholinguistics, 8(4), 429-448. https://doi.org/10.1017/S0142716404001201

Rogé, B. (1989). Echelle d'évaluation de l'autisme infantile-version traduite (CARS-T). EAP/ECPA.

Rutter, M., Le Couteur, A., \& Lord, C. (2003a). ADI-R. Autism diagnostic interview revised. Manual. Los Angeles: Western Psychological Services. (French Adaptation: Rogé, B. et al., 2011, Paris: Editions Hogrefe).

Rutter, M., Bailey, A., \& Lord, C. (2003b). The social communication questionnaire: manual. Western Psychological Services.

Sackett, D. L., Straus, S. E., Richardson, W. S., Rosenberg, W., \& Haynes, R. B. (2000). Evidence-based medicine: How to practice and teach EBM (2nd ed.). Churchill Livingstone. 
Sanders, J., Johnson, K. A., Garavan, H., Gill, M., \& Gallagher, L. (2008). A review of neuropsychological and neuroimaging research in autistic spectrum disorders: Attention, inhibition and cognitive flexibility. Research in Autism Spectrum Disorders, 2(1), 1-16. https://doi.org/10.1016/j.rasd.2007.03.005

Schopler, E., Reichler, R. J., DeVellis, R. F., \& Daly, K. (1980). Toward objective classification of childhood autism: Childhood Autism Rating Scale (CARS). Journal of Autism and Developmental Disorders, 10(1), 91-103. https://doi.org/10. 1007/BF02408436

Schuh, J., \& Eigsti, I. M. (2012). Working memory, language skills, and autism symptomatology. Behavioral Sciences, 2, 207-218. https://doi.org/10.3390/bs2040207

Semel, E., Wiig, E. H., \& Secord, W. A. (2003). Clinical evaluation of language fundamentals, (CELF-4). The Psychological Corporation.

Silleresi, S., Tuller, L., Delage, H., Durrleman, S., Bonnet-Brilhault, F., Malvy, J., \& Prévost, P. (2018). Sentence repetition and language impairment in French-speaking children with ASD. In A. Gavarro (Ed.), On the acquisition of the syntax of Romance (Language Acquisition and Language Disorders) (pp. 235258). John Benjamins.

St Clair-Thompson, H. L. (2010). Backwards digit recall: A measure of short-term memory or working memory? European Journal of Cognitive Psychology, 22(2), 286-296. https://doi.org/10. 1080/09541440902771299

Stanford, E., Durrleman, S., \& Delage, H. (2019). The effect of working memory training on the production of object clitics in Frenchspeaking children with Developmental Language Disorder. American Journal of Speech-Language Pathology, 28(4), 1388-1410. https://doi.org/10.1044/2019_ajslp-18-0238

Stanford, E. (2020). The language-cognition interface: Executive functions and syntax in atypical development. Doctoral dissertation, University of Geneva. Retrieved from https://archive-ouverte. unige.ch/unige: 144700

Stanford, E., \& Delage, H. (2020). Executive functions and morphosyntax: distinguishing DLD from ADHD in French-speaking children. Frontiers in Psychology, 11, 551824. https://doi.org/10.3389/ fpsyg.2020.551824

Tager-Flusberg, H. (1996). Brief report: Current theory and research on language and communication in autism. Journal of Autism and Developmental Disorders, 26, 169-172. https://doi.org/10.1007/ BF02172006

Terzi, A., Marinis, T., Kotsopoulou, A., \& Francis, K. (2014). Grammatical abilities of Greek-speaking children with autism. Language Acquisition, 21(1), 4-44. https://doi.org/10.1080/10489223.2013. 855216

Tuller, L., Delage, H., Monjauze, C., Piller, A. G., \& Barthez, M. A. (2011). Clitic pronoun production as a measure of atypical language development in French. Lingua, 121, 423-441. https://doi. org/10.1016/j.lingua.2010.10.008

Tuller, L., Ferre, S., Prevost, P., Barthez, M., Malvy, J., \& BonnetBrihault, F. (2017). The effect of computational complexity on the acquisition of French by children with ASD. In L. R. Naigles (Ed.), Innovative investigations of language in autism spectrum disorder. American Psychological Association. https://doi.org/10. 1037/15964-007

Tuller, L., Henry, C., Sizaret, E., \& Bathez, M. A. (2012). SLI at adolescence: Avoiding complexity. Applied Psycholinguistics, 33, 161-184. https://doi.org/10.1017/S0142716411000312

Tye, C., Asherson, P., Ashwood, K. L., Azadi, B., Bolton, P., \& McLoughlin, G. (2014). Attention and inhibition in children with ASD, ADHD and co-morbid ASD+ ADHD: An event-related potential study. Psychological Medicine, 44(5), 1101-1116. https://doi.org/10.1017/S0033291713001049
Tzuriel, D. (2001). Dynamic assessment of young children. Kluwer Academic/Plenum. https://doi.org/10.1007/978-1-4615-1255-4_5

Veer, I. M., Luyten, H., Mulder, H., van Tuijl, C., \& Sleegers, P. J. (2017). Selective attention relates to the development of executive functions in 2, 5-to 3-year-olds: A longitudinal study. Early Childhood Research Quarterly, 41, 84-94. https://doi.org/10. 1016/j.ecresq.2017.06.005

Viterbori, P., Usai, M. C., \& Gandolfi, E. (2012). Executive skills and early language development. Executive Skills and Early Language Development, 12(3), 17-32.

Vivanti, G., Fanning, P. A., Hocking, D. R., Sievers, S., \& Dissanayake, C. (2017). Social attention, joint attention and sustained attention in autism spectrum disorder and Williams syndrome: Convergences and divergences. Journal of Autism and Developmental Disorders, 47(6), 1866-1877. https://doi.org/10.1007/ s10803-017-3106-4

Wan, C. Y., Bazen, L., Baars, R., Libenson, A., Zipse, L., Zuk, J., ... Schlaug, G. (2011). Auditory-motor mapping training as an intervention to facilitate speech output in non-verbal children with autism: A proof of concept study. PloS one, 6(9), e25505. https:// doi.org/10.1371/journal.pone.0025505

Wang, Y., Zhang, Y. B., Liu, L. L., Cui, J. F., Wang, J., Shum, D. H., ... Chan, R. C. (2017). A meta-analysis of working memory impairments in autism spectrum disorders. Neuropsychology Review, 27(1), 46-61.https://doi.org/10.1007/s11065-016-9336-y

Wechsler, D. (2005). WISC-IV: Echelle d'Intelligence de Wechsler pour Enfants-4ème édition. ECPA.

Weismer, S. E., Davidson, M. M., Gangopadhyay, I., Sindberg, H., Roebuck, H., \& Kaushanskaya, M. (2017). The role of nonverbal working memory in morphosyntactic processing by children with specific language impairment and autism spectrum disorders. Journal of Neurodevelopmental Disorders, 9(1), 28. https://doi. org/10.1186/s11689-017-9209-6

White, L. J., Alexander, A., \& Greenfield, D. B. (2017). The relationship between executive functioning and language: Examining vocabulary, syntax, and language learning in preschoolers attending Head Start. Journal of Experimental Child Psychology, 164, 16-31. https://doi.org/10.1016/j.jecp.2017.06.010

Williams, D., Botting, N., \& Boucher, J. (2008). Language in autism and specific language impairment: where are the links? Psychological Bulletin, 134(6), 944-963. https://doi.org/10.1037/a0013743

Williams, D., Goldstein, G., \& Minshew, N. J. (2006). The profile of memory function in children with autism. Neuropsychology, 20(1), 21-29. https://doi.org/10.1037/0894-4105.20.1.21

Willis, C. S., \& Gathercole, S. E. (2001). Phonological short-term memory contributions to sentence processing in young children. Memory, 9, 349-364. https://doi.org/10.1080/09658210143000155

Wolk, L., Edwards, M. L., \& Brennan, C. (2016). Phonological difficulties in children with autism: An overview. Speech, Language and Hearing, 19, 121-129. https://doi.org/10.1080/2050571X.2015. 1133488

Zebib, R., Tuller, L., Prévost, P., \& Morin, E. (2013). Formal language impairment in French-speaking children with ASD: A comparative ASD/SLI study. Advances in language acquisition. Cambridge Scholars Publisher.

Zesiger, P., Zesiger, L. C., Arabatzi, M., Baranzini, L., Cronel-Ohayon, S., Franck, J., ... Rizzi, L. (2010). The acquisition of pronouns by French children: A parallel study of production and comprehension. Applied Psycholinguistics, 31(4), 571-603.https://doi.org/ $10.1017 /$ S0142716410000147

Publisher's Note Springer Nature remains neutral with regard to jurisdictional claims in published maps and institutional affiliations. 